\title{
The photochemistry of rhenium(I) tricarbonyl $N$-heterocyclic carbene complexes
}

Jamila G. Vaughan, ${ }^{a}$ Brodie L. Reid, ${ }^{a}$ Sushil Ramchandani, ${ }^{a}$ Phillip J. Wright, ${ }^{a}$ Sara Muzzioli, ${ }^{b}$ Brian W. Skelton, ${ }^{c}$ Paolo Raiteri, ${ }^{a}$ David H. Brown, ${ }^{a} *$ Stefano Stagni, ${ }^{b} *$ Massimiliano Massi ${ }^{a} *$

${ }^{a}$ Department of Chemistry - Curtin University, Kent Street, Bentley 6102 WA, Australia.

${ }^{b}$ Department of Industrial Chemistry "Toso Montanari" - University of Bologna, viale del Risorgimento 4, Bologna 40126, Italy.

${ }^{c}$ Centre for Microscopy, Characterisation and Analysis, University of Western Australia, Crawley 6009 WA, Australia.

\section{Corresponding Authors}

*E-mail: m.massi@curtin.edu.au, stefano.stagni@unibo.it, d.h.brown@curtin.edu.au

\begin{abstract}
The photophysical and photochemical properties of the new tricarbonyl rhenium(I) complexes bound to $N$-heterocyclic carbene ligands $(\mathrm{NHC}), f a c-\left[\operatorname{Re}(\mathrm{CO})_{3}\left(\mathbf{N}^{\wedge} \mathbf{C}\right) \mathrm{X}\right]\left(\mathbf{N}^{\wedge} \mathbf{C}=\right.$ 1-phenyl-3-(2-pyridyl)imidazole or 1-quinolinyl-3-(2-pyridyl)imidazole; $\mathrm{X}=\mathrm{Cl}$ or $\mathrm{Br}$ ), are reported. The photophysics of these complexes highlight phosphorescent emission from triplet metal-to-ligand $\left({ }^{3}\right.$ MLCT) excited states, typical of tricarbonyl rhenium(I) complexes, with the pyridyl-bound species displaying a ten-fold shorter excited state lifetime attributed to thermally accessible quenching excited states. On the other hand, these pyridyl-bound species display solvent-dependent photochemical CO dissociation following what appear to be two different mechanisms, with a key step being the formation of cationic tricarbonyl solvatocomplexes, being themselves photochemically active. The photochemical mechanisms are illustrated with a combination of NMR, IR, UV-Vis, emission and X-ray structural characterization techniques, clearly demonstrating that the presence of the NHC ligand is responsible for the previously unobserved photochemical behavior in other photoactive tricarbonyl rhenium(I) species. The complexes bound to the quinolinyl-NHC ligand (which possess a lower-energy ${ }^{3} \mathrm{MLCT}$ ) are photostable, suggesting that the photoreactive excited state is not any longer thermally accessible. The photochemistry of the pyridyl complexes was investigated in acetonitrile solutions and also in the presence of triethylphosphite, showing a
\end{abstract}


competing and bifurcated photoreactivity promoted by the trans effect of both the NHC and phosphite ligands.

\section{Introduction}

The photophysics of rhenium(I) tricarbonyl diimine complexes, fac$\left[\operatorname{Re}(\mathrm{CO})_{3}(\operatorname{diim})(\mathbf{L})\right]^{0 /+}$, where $\operatorname{diim}$ is a diimine-type ligand and $\mathbf{L}$ a monodentate ancillary ligand, has been studied since the pioneering work of Wrighton and Morse. ${ }^{1,2}$ These complexes typically exhibit phosphorescent emission from their lowest-lying triplet metal-toligand charge transfer excited state, ${ }^{3} \mathrm{MLCT}$, characterized by good quantum yields, long excited state lifetime and large Stokes shifts. ${ }^{3,4}$ These properties make this class of compounds promising candidates for a variety of applications, including light-emitting devices, ${ }^{5-7}$ biological labels ${ }^{8,9}$ and photocatalysis. ${ }^{10}$

In comparison to their photophysics, the photochemistry of these complexes has received relatively limited attention. ${ }^{3,11}$ Early studies by Spellane, Ishitani and Sullivan reported the photochemical $\mathrm{CO}$ dissociation in rhenium(I) tricarbonyl complexes bound to phosphorous-donor ligands. ${ }^{12-18}$ By exploiting the strong trans effect of phosphine and phosphite ligands, examples of rhenium(I) dicarbonyl species were photochemically synthesized. Ko reported an analogous photochemical ligand substitution reaction on rhenium(I) isonitrile complexes. ${ }^{19-22}$ In a similar fashion, the trans effect of the isonitrile ligand was exploited to substitute the $\mathrm{CO}$ ligand upon photoexcitation. The photochemical CO substitution was shown to occur via a dissociative mechanism from a reactive ligand field excited state of triplet multiplicity, ${ }^{3} \mathrm{LF},{ }^{23}$ which can be thermally accessible from the lowerlying emissive ${ }^{3}$ MLCT state. The Re-CO dissociation occurs as a consequence of the distortion caused by the population of the ${ }^{3} \mathrm{LF}$ state, coupled with the labilization of the CO opposite to the ligand displaying a strong trans effect. ${ }^{23}$ It was also shown that, after the dissociation of the CO ligand, no scrambling of the other two CO ligands occurs, hence the new entering ligand always coordinates trans to the labilizing ligand, yielding only one of the three possible geometrical isomers (or two isomers in case of $C_{2}$-symmetrical diim ligands). ${ }^{23}$

More recently, Ishitani reported the photochemical $\mathrm{CO}$ substitution of fac$\left[\operatorname{Re}(\mathrm{CO})_{3}(\right.$ bipy $\left.) \mathrm{Cl}\right]$, where bipy $=2,2^{\prime}$-bipyridine. ${ }^{24,25}$ This complex lacks the coordination of a labilizing ligand such as phosphine, phosphite or isonitrile and it is photostable when its lowest-lying triplet manifold is populated. However, the population of higher excited states results in the cleavage of a $\mathrm{Re}-\mathrm{CO}$ bond and ligand exchange with formation of multiple 
geometrical isomers. These isomers are obtained as a consequence of dissociative mechanisms occurring on excited states of LF character, associative mechanisms on excited states of MLCT character as well as thermally induced isomerization. ${ }^{25}$

We have recently reported the synthesis and photophysical characterization of the tricarbonyl rhenium(I) $N$-heterocyclic carbene (NHC) complexes $\mathbf{1 C l}$ and $\mathbf{1 B r}$, whose structures are shown in Figure $1 .{ }^{26}$ We noted in our investigation that the emission spectra of these complexes changed over time, as highlighted by the disappearance of their emission bands around $510 \mathrm{~nm}$ and the concomitant appearance of red-shifted and structureless bands around $600 \mathrm{~nm}^{26}$ The investigation of this behavior has led to the discovery that tricarbonyl rhenium(I) NHC complexes are photochemically active and undergo CO substitution reaction when excited to their lowest lying ${ }^{3}$ MLCT state. The initial explanation involved the coordination of the strongly $\sigma$-donating $\mathrm{C}$ atom of the NHC ligand, ${ }^{27,28}$ thus promoting the labilization of the $\mathrm{CO}$ in trans from excited states of ${ }^{3} \mathrm{LF}$ nature ${ }^{23}$ however, the analysis of the experimental data revealed the formation of three different complexes. While this behavior appears unprecedented with respect to the previous two classes of photoactive rhenium(I) tricarbonyl complexes, ${ }^{23,25}$ our studies suggest that, in the case of the present species there might be an interplay between the direct substitution of a CO ligand, forming a dicarbonyl solvato-complex, and the halogen ancillary ligand, yielding a photoactive cationic tricarbonyl solvato-complex: both of these processes are promoted upon photoexcitation to the lowest ${ }^{3}$ MLCT excited state.

To elucidate the underlying photochemical mechanisms, we used an approach based on synthetic chemistry and simpler conventional spectroscopy, rather than an investigation centered on more sophisticated time-resolved ultrafast measurements. ${ }^{23,25,29,30}$ For this scope, a family of four new rhenium(I) tricarbonyl complexes bound to two different NHC ligands was prepared (Figure 1): the variation in the NHC ligand was designed to modulate, in a controlled manner, the relative energy gap between the emissive ${ }^{3}$ MLCT excited state and higher reactive excited states. ${ }^{3}$ 


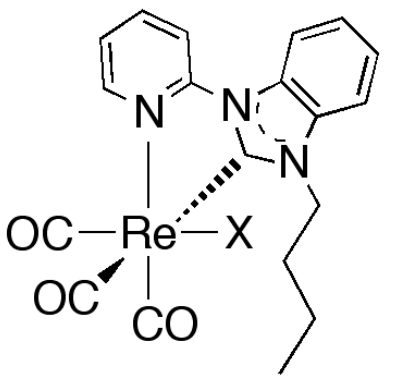

$1 \mathrm{Cl}: \mathrm{X}=\mathrm{Cl}$

1Br: $\mathrm{X}=\mathrm{Br}$

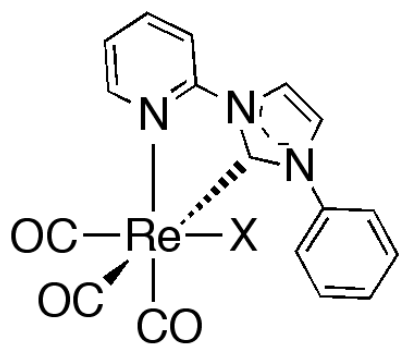

2Cl: $\mathrm{X}=\mathrm{Cl}$

2Br: $\mathrm{X}=\mathrm{Br}$

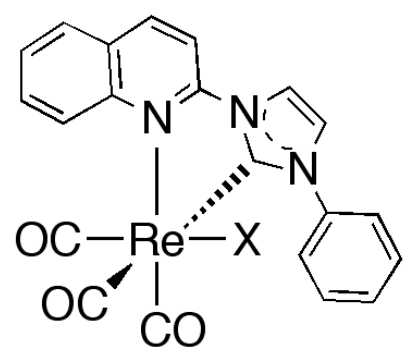

$3 \mathrm{Cl}: \mathrm{X}=\mathrm{Cl}$

3Br: $\mathrm{X}=\mathrm{Br}$

Figure 1. Structures of the previously reported complexes $(\mathbf{1 C l}$ and $\mathbf{1 B r})$ and the complexes investigated in this work (2Cl, $\mathbf{2 B r}, \mathbf{3 C l}$ and $\mathbf{3 B r})$.

\section{Results and Discussion}

\section{Synthesis and structural characterization of the complexes}

Similarly to published procedures, the NHC precursors 1-phenyl-3-(2pyridyl)imidazolium (PyImPhH·X) and 1-quinolinyl-3-(2-pyridyl)imidazolium salts $(\mathrm{QiImPhH} \cdot \mathrm{X})$, where $\mathrm{X}$ is $\mathrm{Cl}, \mathrm{Br}$ or $\mathrm{PF}_{6}$ depending on the specific targeted complex, were prepared by nucleophilic substitution of 1-phenylimidazole with either 2-chloro or 2bromopyridine, followed if needed by metathesis with $\mathrm{KPF}_{6}{ }^{26,31}$ Following our previous report, the complexes $\mathbf{2 C l}, \mathbf{2 B r}, \mathbf{3 C l}$ and $\mathbf{3 B r}$ were synthesized, as racemic mixtures, by reaction of $\left[\operatorname{Re}(\mathrm{CO})_{5} \mathrm{X}\right]$ and the corresponding PyImPhH $\cdot \mathrm{X}$ or QiImPhH.X ligand in the presence of triethylamine. ${ }^{26}$ The complexes were analyzed by NMR, IR, elemental analysis as well as X-ray diffraction, with the experimental data in agreement with the proposed formulations. In particular, the structural analysis reveals that all the complexes possess the three carbonyl ligands in facial configuration, as expected by the substitution of two $\mathrm{CO}$ ligands in $\left[\operatorname{Re}(\mathrm{CO})_{5} \mathrm{X}\right]$ with a neutral bidentate species. ${ }^{3}$ The structures of $\mathbf{2 C l}, \mathbf{2 B r}, \mathbf{3 C l}$ and 3Br are shown in Figure 2 (see ESI for tables reporting bond lengths and angles). In agreement with the structural studies, all the complexes present three intense peaks in the IR spectra corresponding to the three CO ligands, confirming the $C_{1}$ point group of the species. The lack of symmetry of the complexes is also confirmed by the presence of three distinct peaks in their ${ }^{13} \mathrm{C}-\mathrm{NMR}$ spectra belonging to the $\mathrm{CO}$ ligands. The frequency values of the $\mathrm{CO}$ peaks of the four complexes are similar and analogous to other previously reported 
tricarbonyl rhenium(I) NHC species, ${ }^{26,32}$ revealing that the substitution of the pyridine ring for a quinoline moiety in the chelating PyImPh ligand does not significantly alter the electron density on the Re centers.
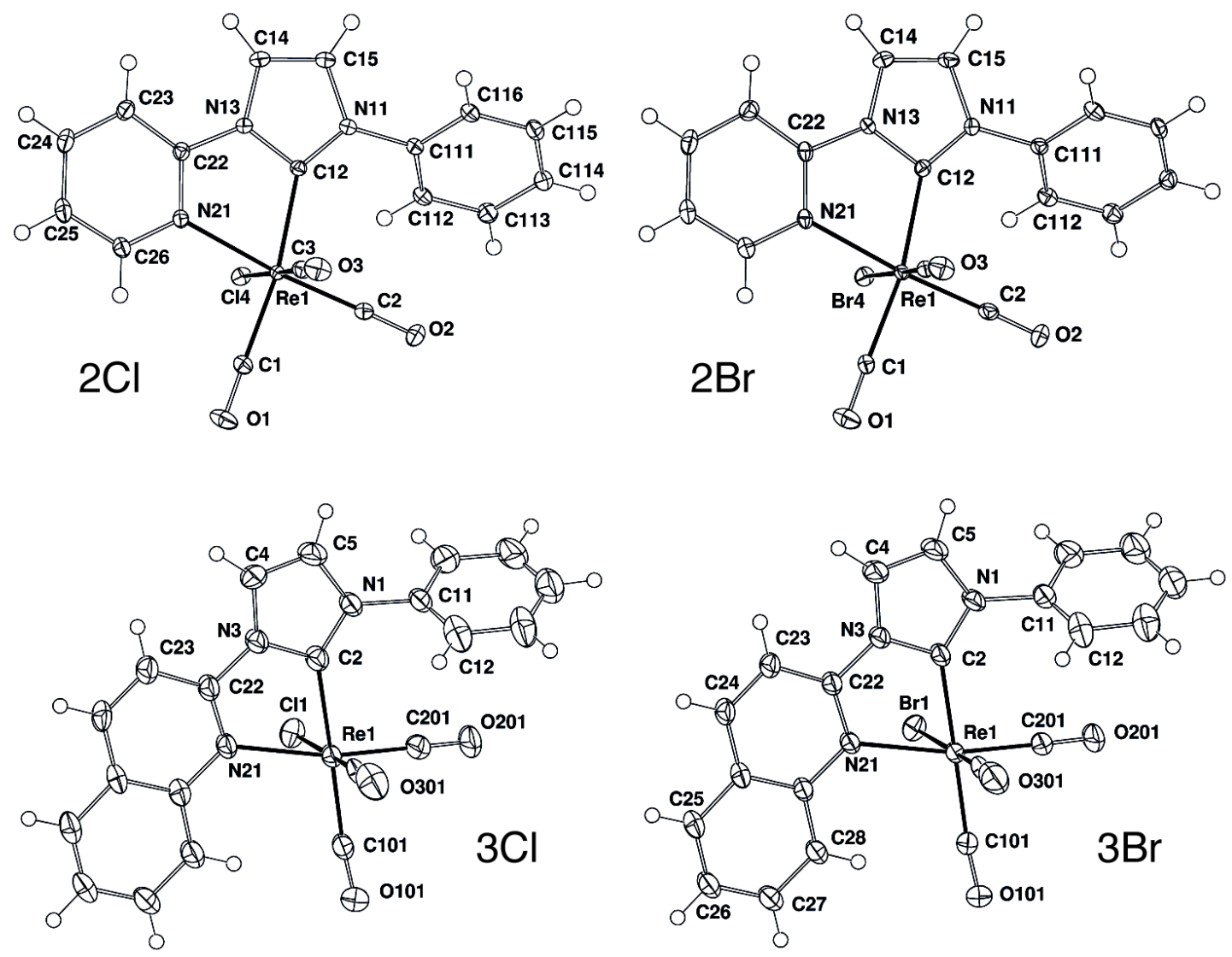

Figure 2. X-ray crystal structures of the synthesized complexes $\mathbf{2 C l}, \mathbf{2 B r}, \mathbf{3 C l}$ and $\mathbf{3 B r}$ with ellipsoids drawn at the $50 \%$ probability level.

\section{Photophysical investigation}

A summary of the photophysical data is reported in Table 1. The absorption profiles are analogous for the four complexes (see Figure 3 for the representative chloro complexes $\mathbf{2 C l}$ and $3 \mathbf{C l}$; the remaining profiles of the bromo complexes are reported in the ESI). All the spectra present high energy transitions in the $250-300 \mathrm{~nm}$ region, followed by red-shifted bands of lower intensity. Following previous studies on analogous complexes, ${ }^{26,32,3}$ the high energy band has been assigned to $\pi-\pi^{*}$ ligand centered (LC) transitions localized on the chelating NHC ligands. On the other hand, the lowest energy bands are ascribed to $\mathrm{S}_{0} \rightarrow$ ${ }^{1}$ MLCT transitions, with a contribution of ligand-to-ligand charge transfer (LLCT, $\mathrm{X} \rightarrow$ 
NHC). ${ }^{4}$ A further shoulder, in the case of $\mathbf{3 C l}$, and a structured band, for $\mathbf{3 B r}$, are visible in the corresponding absorption profiles in the 300-350 nm region. Similar features are also present in the absorption spectra of the NHC salts PyImPhH.Cl and QiImPhH.Cl, suggesting these processes are not characterized by a MLCT nature but rather by LC character. An analysis of the $\lambda_{\mathrm{abs}}$ for the MLCT transitions reveals a red-shift of $\Delta \lambda=31 \mathrm{~nm}$ and $\Delta \lambda=17 \mathrm{~nm}$ for the pairs of chloro and bromo complexes, respectively. The lowering in energy of the corresponding MLCT excited states for the complexes coordinated to the quinolinyl-NHC ligands can be rationalized by the increased conjugation on passing from the pyridyl to the quinolinyl substituent on the imidazole ring.

Table 1. Summary of the photophysical data from diluted $\left(c a .10^{-5} \mathrm{M}\right)$ dichloromethane solutions.

\begin{tabular}{llcccc}
\hline & Conditions & $\lambda_{\text {abs }}[\mathbf{n m}]\left(\mathbf{1 0}^{4} \varepsilon\left[\mathbf{M}^{-1} \mathbf{c m}^{-1}\right]\right)$ & $\lambda_{\text {em }}[\mathbf{n m}]$ & $\boldsymbol{\tau}[\boldsymbol{\mu s}]$ & $\boldsymbol{\Phi}^{a}$ \\
\hline $\mathbf{2 C l}$ & DCM - air equil. & $277(0.89), 361(0.33)$ & 522 & 0.060 & 0.03 \\
& DCM - dear. & & 0.140 & 0.09 \\
& DCM - 77 K & & 482 & 5.167 & \\
$\mathbf{2} \mathbf{2 B r}$ & DCM - air equil. & $275(1.13), 365(0.38)$ & 516 & 0.019 & 0.02 \\
& DCM - dear. & & 0.023 & 0.03 \\
& DCM - 77 K & & 474 & 5.634 & \\
$\mathbf{3 C l}$ & DCM - air equil. & 257(4.73), 336(0.76), 392(0.38) & 626 & 0.240 & 0.03 \\
& DCM - dear. & & & 1.065 & 0.13 \\
& DCM - 77 K & & 552 & 14.443 & \\
$\mathbf{3 B r}$ & DCM - air equil. & $255(3.15), 323(0.77), 382(0.36)$ & 622 & 0.263 & 0.03 \\
& DCM - dear. & & & 0.993 & 0.10 \\
& DCM - 77 K & & 562 & 14.981 &
\end{tabular}

${ }^{a}$ The measurement of the quantum yield was performed using an air-equilibrated aqueous solution of $\left[\mathrm{Ru}(\mathbf{b i p y})_{3}\right] \mathrm{Cl}_{2}\left(\Phi_{r}=0.028\right)$ as reference.

Upon excitation into their respective ${ }^{1}$ MLCT manifolds, all the complexes exhibit broad and structureless emission bands (see Figure 3 for the representative chloro complexes $\mathbf{2 C l}$ and $\mathbf{3 C l}$; the remaining profiles of the bromo complexes are reported in the ESI). Following the same trend observed for the absorption profiles, the emission $\lambda_{\mathrm{em}}$ for the pyridyl-NHC complexes $\mathbf{2 C l}$ and $\mathbf{2 B r}$ are blue-shifted of $\Delta \lambda=104 \mathrm{~nm}$ between the two chloro complexes and $\Delta \lambda=106 \mathrm{~nm}$ between the two bromo complexes. At $77 \mathrm{~K}$, all the complexes exhibit blue-shifted $\lambda_{\text {em }}$ caused by rigidochromism, ${ }^{33-36,1}$ (see ESI for the excitation and emission profiles from dichloromethane solutions of the complexes at $77 \mathrm{~K}$ ). 
The excited state lifetime $(\tau)$ of the complexes ranges from tens to hundreds of nanoseconds and in all cases it is sensitive to the presence of $\mathrm{O}_{2}$, with the same trend being observed for the variation of the quantum yield $\Phi$. This behavior indicates that the emission originates from an excited state of triplet multiplicity, which is likely of prevalent ${ }^{3}$ MLCT nature, as suggested by the broad and structureless emission profiles. Noteworthy, the values of $\tau$ for the quinolinyl-NHC complexes $\mathbf{3 C l}$ and $\mathbf{3 B r}$ in degassed solutions are $c a$. one order of magnitude longer than the corresponding pyridyl-NHC $\mathbf{2 C l}$ and $\mathbf{2 B r}$ complexes. The elongation could be a consequence of the lowered ${ }^{3} \mathrm{MLCT}$ energy for the former complexes reducing thermal population to higher quenching excited states; however, it cannot be excluded that the extended conjugation of the quinolinyl moiety is also favoring longer values of $\tau$ by adding LC character to the MLCT excited state. ${ }^{37,38}$
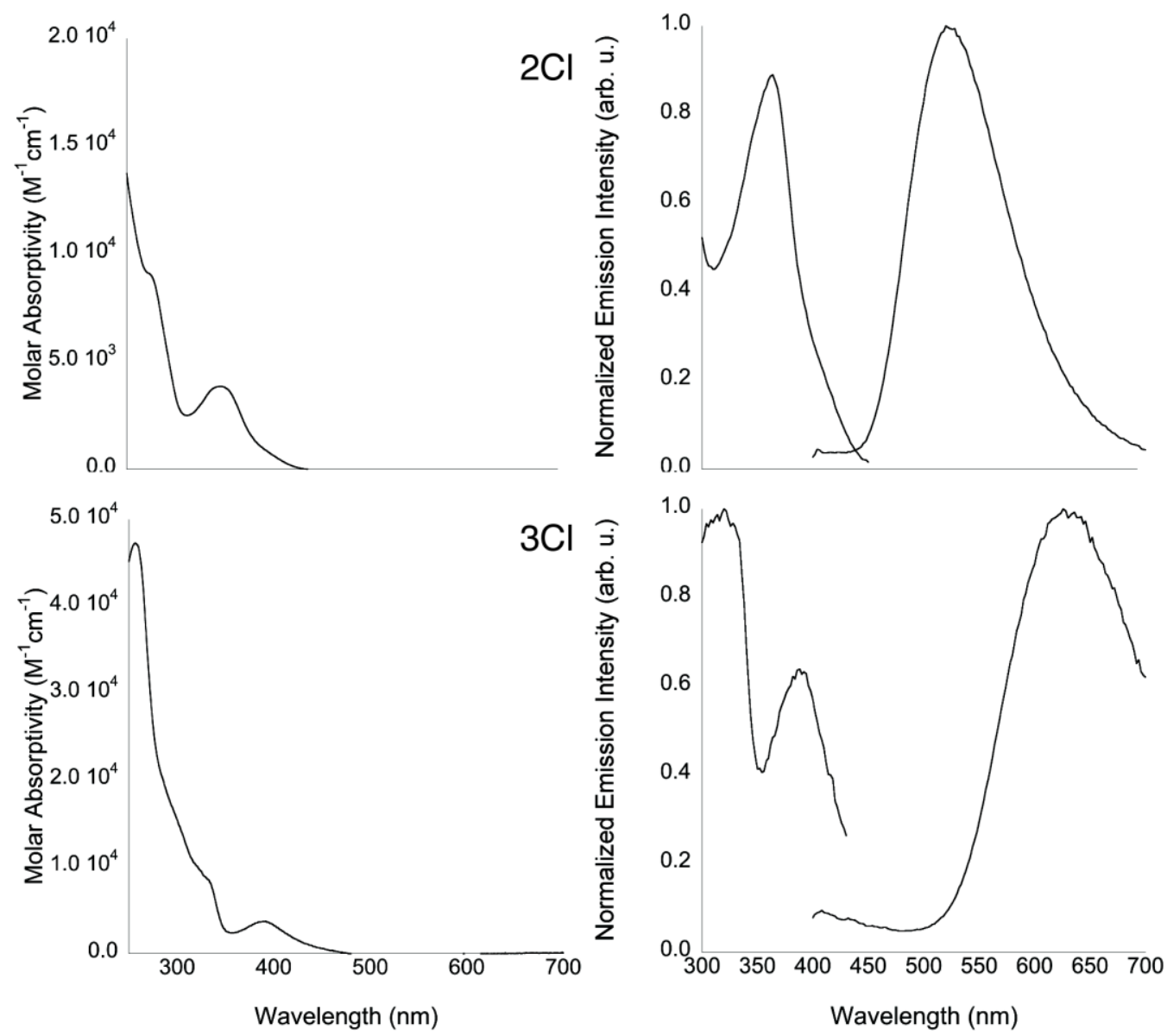

Figure 3. Absorption, excitation and emission profiles for the chloro complexes. The excitation profiles were measured by monitoring the intensity of the corresponding emission maxima. 


\section{Computational calculations}

To validate the interpretation of the photophysical data, the energetics and absorption spectra of the complexes were simulated with time-dependent density functional theory (TDDFT; see ESI for calculated orbital contours and tables of calculated transitions). ${ }^{36}$ According to the calculations, the lower energy transitions originating from the relaxed structures involve the promotion of one electron from the HOMO-n $(n=0,1)$ orbitals to the LUMO $+\mathrm{m}(\mathrm{m}=0,1)$ orbitals, in the case of $\mathbf{2} \mathbf{C l}$ and $\mathbf{2 B r}$, and to the LUMO orbitals for $\mathbf{3 C l}$ and $3 \mathrm{Br}$. As it can be seen from the respective orbital contours, shown in Figure 4, these transitions possess an MLCT character partially mixed with LLCT character, in agreement with the band assignments in the absorption and emission plots. The high energy transitions in the 250-300 nm region belong, in all cases, to $\pi-\pi^{*}$ LC transitions. Furthermore, the calculations show that the additional transitions in the 300-350 $\mathrm{nm}$ region of the absorption spectra for the $\mathbf{3 C l}$ and $\mathbf{3 B r}$ complexes are mainly originating from the HOMO-4 $\rightarrow$ LUMO transition and they are therefore correctly assigned to a $\pi-\pi^{*} \mathrm{LC}$ transition occurring on the quinolinyl-NHC ligand.

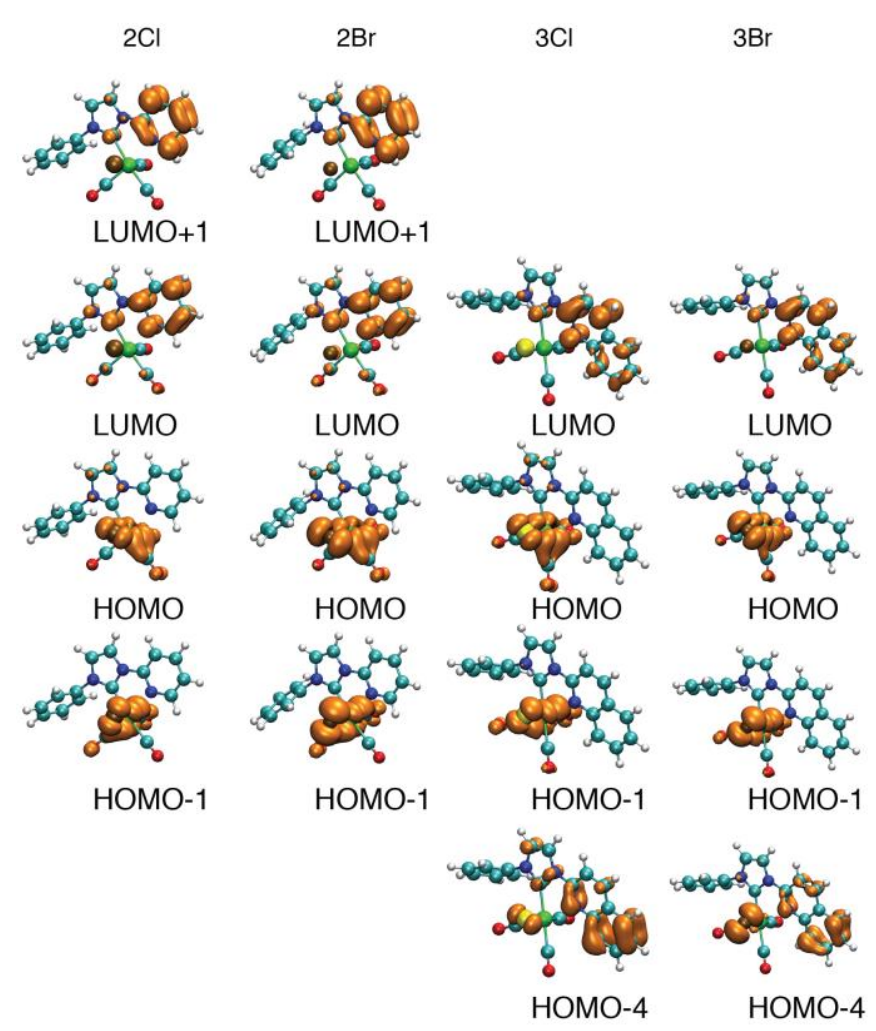

Figure 4. Selected orbital contours relative to the lower energy transitions for the complexes. 


\section{Photochemical investigation: results}

In a similar manner to the previously reported complexes $\mathbf{1 C l}$ and $\mathbf{1 B r},{ }^{26}$ the emission profiles of $\mathbf{2} \mathbf{C l}$ and $\mathbf{2 B r}$ changed over time. The change is characterized by the disappearance of the aqua-colored emission centered at 522 and $516 \mathrm{~nm}$, respectively, and the concomitant appearance of an orange-colored emission centered at 590 and $584 \mathrm{~nm}$, respectively. In an illustrative experiment, the emission profiles of diluted acetonitrile solutions of $\mathbf{2 C l}$ and $\mathbf{2 B r}$ were monitored by recording consecutive spectra upon constant excitation, at $\lambda_{\mathrm{ex}}=370 \mathrm{~nm}$, for 4 hours. The initial and final absorption and emission profiles for both the $\mathbf{2 C l}$ and $\mathbf{2 B r}$ solutions are shown in Figure 5. The change in emission is accompanied by a marked change in the absorption profiles, specifically related to the region of the MLCT transitions. The initial MLCT band appears to split into two new bands, one of which is blue-shifted by ca. 20 $\mathrm{nm}$ and another one red-shifted by approximately the same quantity. The bathochromic shift of one of the components of the initial MLCT transition is in agreement with the red-shifted emission band, indicative of an emissive ${ }^{3}$ MLCT of lower energy compared to that of the initial complexes. Also, the change in the absorption spectra can be visually witnessed by the pale yellow color of the initial solutions progressively becoming dark yellow/orange. It should be noted, however, that if only two spectra are collected initially and after 4 hours, without constant excitation but keeping the solution in the dark, the measured profiles are superimposable. This behavior demonstrates that the changes in the photophysical characteristics of $\mathbf{2} \mathbf{C l}$ and $\mathbf{2 B r}$ have a photochemical rather than thermal origin. Remarkably, no changes were observed in the absorption or emission profiles of acetonitrile solutions of $\mathbf{3 C l}$ and $\mathbf{3 B r}$ when irradiated at $\lambda_{\mathrm{ex}}=370 \mathrm{~nm}$ under identical experimental conditions. 

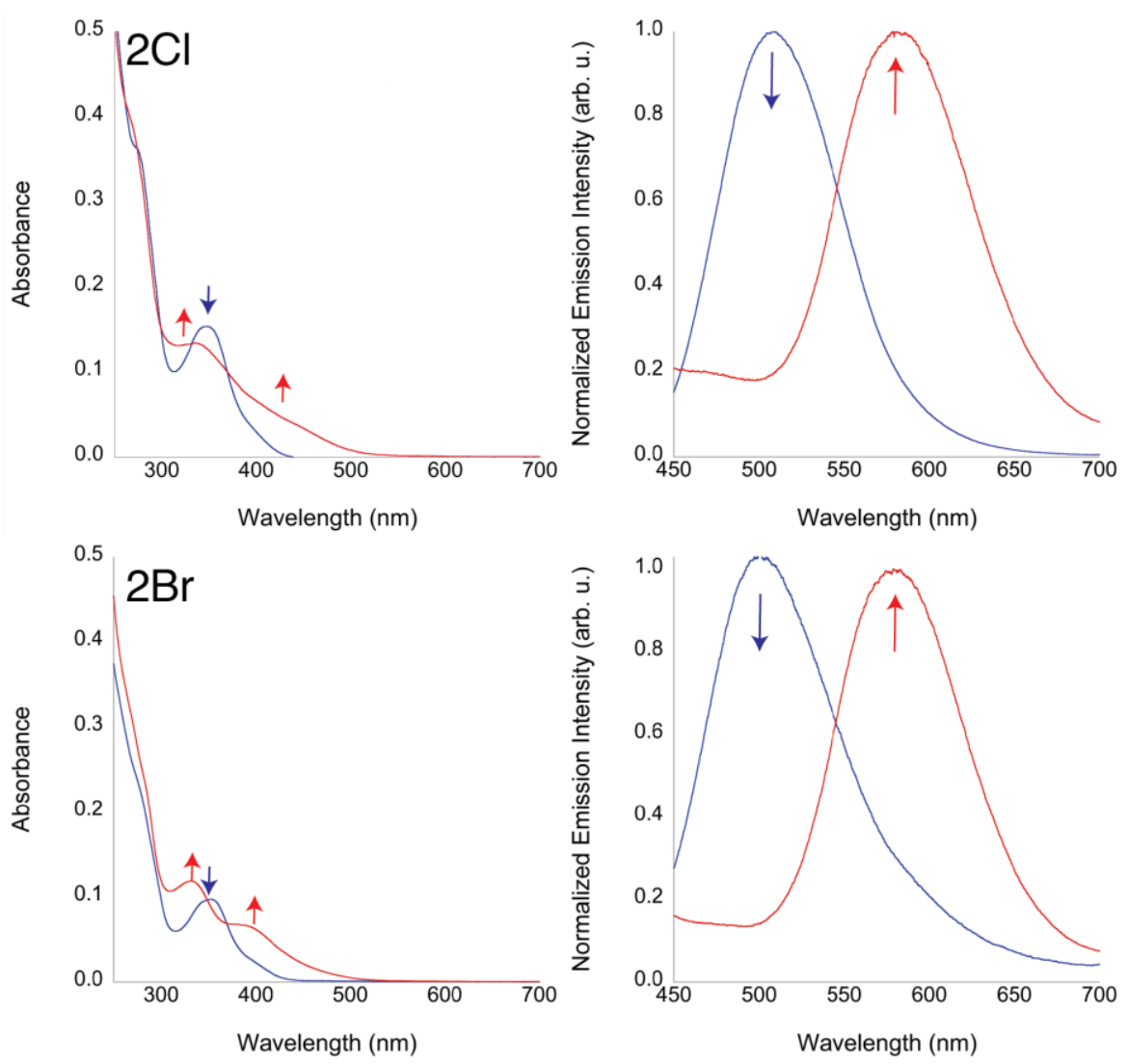

Figure 5. Initial (blue) and final (red, after 4 hours continuous excitation at $\lambda_{\mathrm{ex}}=370 \mathrm{~nm}$ ) absorption and emission profiles for diluted acetonitrile solutions of $\mathbf{2 C l}$ and $\mathbf{2 B r}$.

The photochemical transformation was then monitored by exposing a degassed solution of $\mathbf{2 C l}$ and $\mathbf{2 B r}$ in deuterated acetonitrile, contained within an NMR glass tube, to the radiation of a UV lamp at $\lambda_{\mathrm{ex}}=365 \mathrm{~nm}$. The reaction was followed initially by recording a ${ }^{1} \mathrm{H}-\mathrm{NMR}$ spectrum every 15 minutes for 1 hour and then every 30 minutes for the remaining 2 hours. At the end of the photolysis, both solutions were analyzed by means of IR spectroscopy, focusing on changes of the carbonyl stretching peaks between 2050 and 1800 $\mathrm{cm}^{-1}$. The progression of the ${ }^{1} \mathrm{H}-\mathrm{NMR}$ spectra as well as the IR spectra of the photolyzed acetonitrile solutions are reported in Figures 6 and 7, respectively (see ESI for the complete NMR spectra). The ${ }^{1} \mathrm{H}-\mathrm{NMR}$ investigation of the photochemical evolution of $\mathbf{2} \mathbf{C l}$ and $\mathbf{2 B r}$ was performed considering the signals corresponding to the pyridyl H6 atom of the NHC ligand, as the resolution of the remaining signals is more complicated due to overlapping. As it can be seen from the sequences in Figure 6, the initial doublets at $8.88 \mathrm{ppm}$ for the pyridyl H6 atom of both $\mathbf{2} \mathbf{C l}$ and $\mathbf{2 B r}$ progressively disappear and three new upfield doublets sequentially grow in intensity during the photolysis. The new set of signals appears at almost identical positions for the two complexes: $8.85,8.77,8.75 \mathrm{ppm}$ for the photolysis of $\mathbf{2 C l}$ and 
8.85, 8.78, 8.73 ppm for $\mathbf{2 B r}$. After 3 hours of photolysis, the products resulting from the solution containing $\mathbf{2 C l}$ are mainly those with signals at 8.77 and $8.75 \mathrm{ppm}$, which appear as two almost overlapping doublets (forming an apparent triplet). On the other hand, in the case of $2 \mathrm{Br}$ the three species are present at a ratio of 3:2:5 for the corresponding more resolved signals at $8.85,8.78,8.73 \mathrm{ppm}$, from which a total conversion of $c a .88 \%$ of the initial complex can be calculated by comparing the sum of these three peaks with the remaining doublet of the starting material $\mathbf{2 B r}$. When the same photolysis experiments were carried out on deuterated acetone solutions of $\mathbf{2} \mathbf{C l}$ and $\mathbf{2 B r}$, the spectra remained substantially unaltered (see ESI). A downfield doublet of low integration is evident in the case of $\mathbf{2 B r}$, and this signal appears more intense in wet acetone solutions. Therefore it was tentatively attributed to a possible detachment of the NHC ligand with further hydrolysis, but the complete characterization of this product has not been performed yet. No changes were noted in the sequence of ${ }^{1} \mathrm{H}$-NMR spectra in deuterated chloroform for $\mathbf{2 C l}$ and $\mathbf{2 B r}$ (see ESI). 


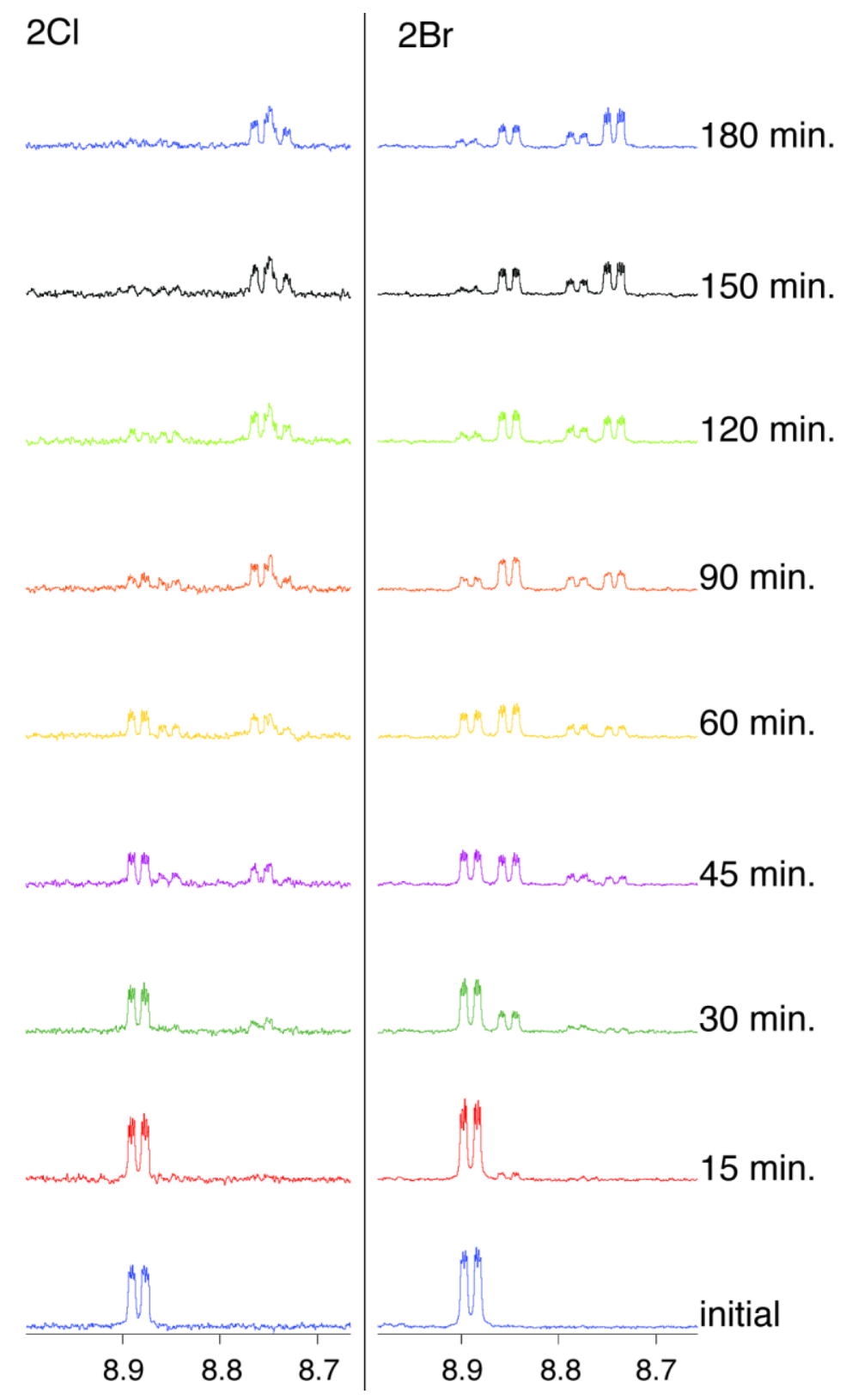

Figure 6. Sequential ${ }^{1} \mathrm{H}-\mathrm{NMR}$ spectra, following the progression of the pyridyl H6 atom, for the photolysis of deuterated acetonitrile solutions of $\mathbf{2 C l}$ (left) and $\mathbf{2 B r}$ (right) exposed to radiation at $\lambda_{\mathrm{ex}}=365 \mathrm{~nm}$.

The IR spectrum of the photolyzed 2Cl solution in acetonitrile (Figure 7) shows the presence of two pairs of carbonyl peaks at $1937,1863 \mathrm{~cm}^{-1}$ and $1917,1831 \mathrm{~cm}^{-1}$. Residual peaks of lower intensity are also visible at 2036 and $2018 \mathrm{~cm}^{-1}$. On the other hand, the IR spectrum of the photolyzed 2Br solution (Figure 7) shows a pair of two intense peaks at 1938, $1863 \mathrm{~cm}^{-1}$ as well as a pair of lower intensity at $1918,1833 \mathrm{~cm}^{-1}$. A more prominent band at $2036 \mathrm{~cm}^{-1}$ is also evident, accompanied to what looks like a peak of very low intensity around $2016 \mathrm{~cm}^{-1}$. Importantly, it should be noted that in both cases, an intense peak at $c a .2260 \mathrm{~cm}^{-1}$, 
attributed to the $\mathrm{CN}$ stretching of acetonitrile, was accompanied by a sharp peak of lower intensity at $c a .2293 \mathrm{~cm}^{-1}$, which suggested the presence of coordinated acetonitrile. ${ }^{39,40}$
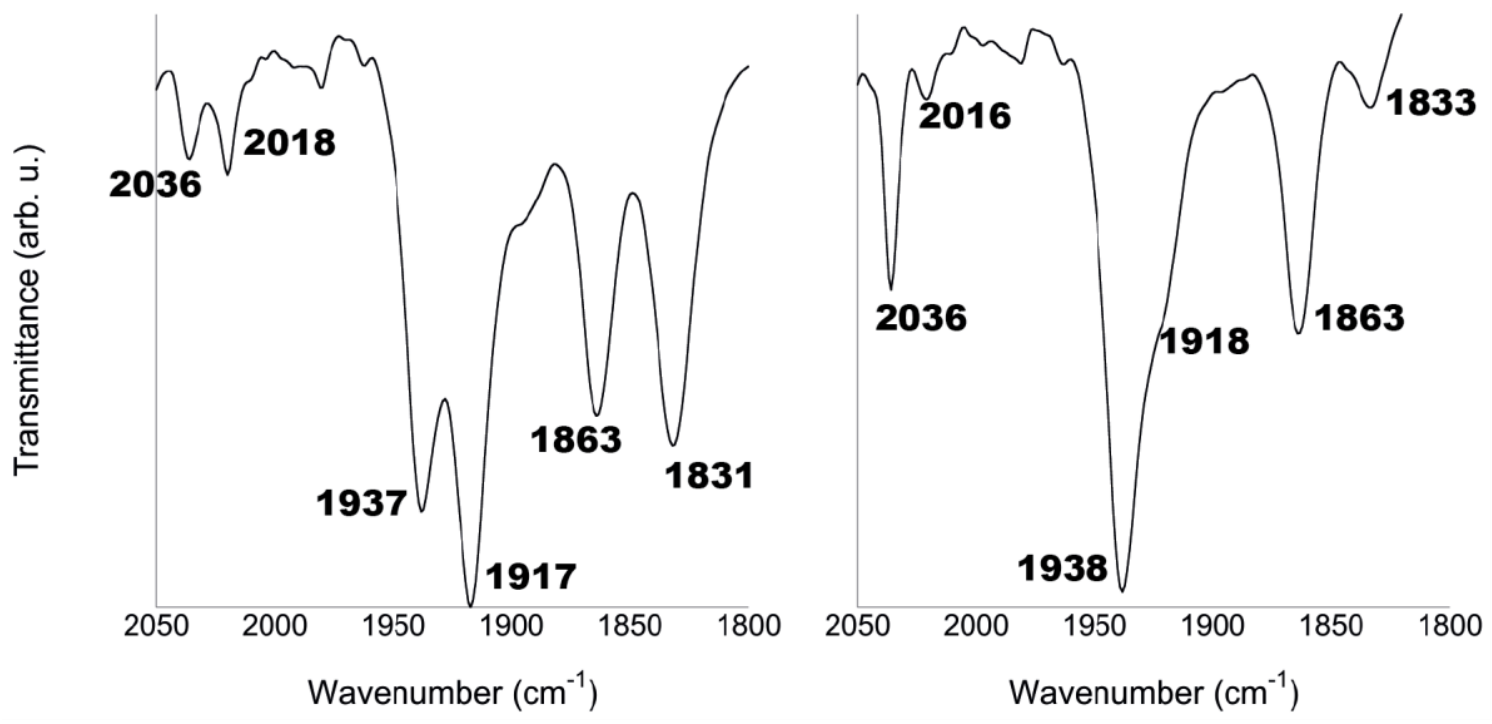

Figure 7. IR spectra of the photolyzed acetonitrile solutions of $2 \mathbf{C l}$ (left) and $2 \mathbf{B r}$ (right). The photolysis was performed by irradiating the solutions at $\lambda_{\mathrm{ex}}=365 \mathrm{~nm}$ for a combined total amount of 3 hours.

After several attempts, the crystallization of a photolyzed acetonitrile solution of $\mathbf{2 C l}$ yielded a small crop of crystals suitable for X-ray diffraction, mixed with amorphous solids. The structural identification revealed this product was the dicarbonyl complex cis,cis$\left[\mathrm{Re}(\mathrm{CO})_{2}(\mathbf{P y I m P h})\left(\mathrm{NCCH}_{3}\right) \mathrm{Cl}\right]$, where an acetonitrile molecule has exchanged for a $\mathrm{CO}$ ligand in trans to the $\mathrm{C}$ atom of the NHC ligand (Figure 8). The IR spectrum of the isolated crystals reveals, in the solid state, carbonyl bands at 1903 and $1815 \mathrm{~cm}^{-1}$ along with a peak at $2293 \mathrm{~cm}^{-1}$ ascribed to the $\mathrm{CN}$ group of the coordinated acetonitrile solvent. Therefore, the presence of this dicarbonyl species was attributed in the solution IR shown in Figure 7 (spectrum on the left hand side) to the pair of bands at 1917 and $1831 \mathrm{~cm}^{-1}$.

A modified photolysis regime was then designed: (i) each solution was photolyzed for 15 minutes under the same conditions described earlier; (ii) the ${ }^{1} \mathrm{H}-\mathrm{NMR}$ spectrum was recorded; (iii) the same solution was then heated in the dark up to a temperature of $70{ }^{\circ} \mathrm{C}$ for 2 hours; and (iv) a further ${ }^{1} \mathrm{H}-\mathrm{NMR}$ spectrum was recorded to monitor any changes that occurred to the solution whilst the compound was heated in the dark, before repeating the four-step process. While changes in the ${ }^{1} \mathrm{H}$-NMR spectra were detected after each photolysis 
session, following the trend previously described, no change was noticeable when the solutions were heated in the dark, either in the case of $\mathbf{2 C l}$ or that of $\mathbf{2 B r}$ (see ESI).

As expected from the absorption and emission profiles, no changes were recorded in the ${ }^{1} \mathrm{H}-\mathrm{NMR}$ spectra from the photolysis experiments of $\mathbf{3 C l}$ and $\mathbf{3 B r}$ from deuterated acetonitrile, acetone or chloroform solutions (see ESI).

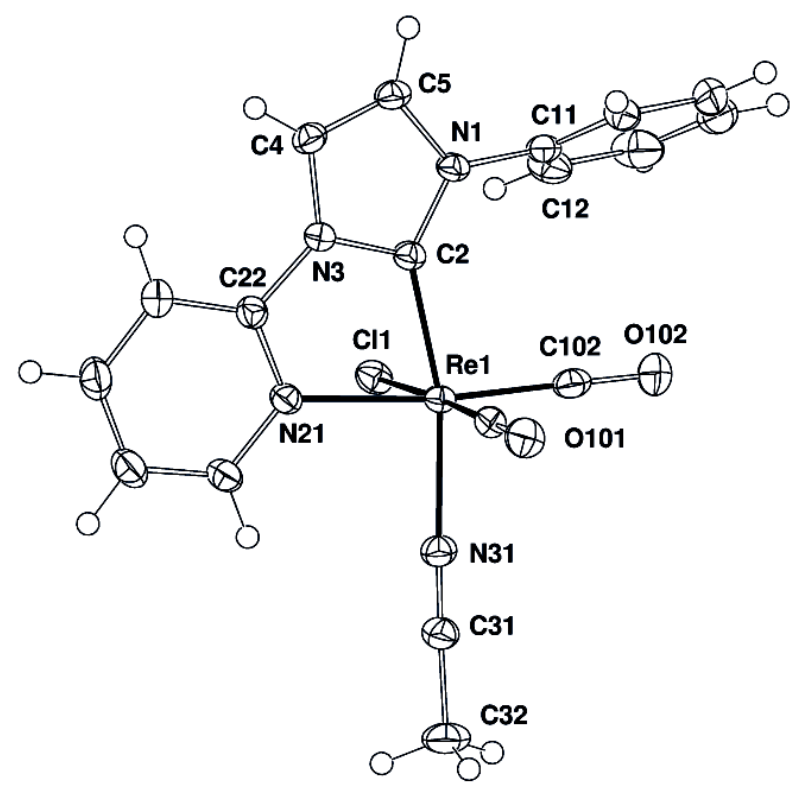

Figure 8. X-ray crystal structure of $f a c-\left[\operatorname{Re}(\mathrm{CO})_{2}(\mathbf{P y} \mathbf{I m P h})\left(\mathrm{NCCH}_{3}\right) \mathrm{Cl}\right]$ with ellipsoids drawn at the $50 \%$ probability level.

\section{Photochemical investigation: discussion}

The first set of conclusions that can be drawn by analyzing the results presented on the photolysis experiments are: i) both $\mathbf{2 C l}$ and $\mathbf{2 B r}$ are photoactive when excited to their lowest MLCT state in acetonitrile solutions; ii) the photolysis of $\mathbf{2 C l}$ and $\mathbf{2 B r}$ is solvent-dependent, occurring in acetonitrile but not in acetone or chloroform; iii) all the transformations occurring on the $\mathbf{2 C l}$ and $\mathbf{2 B r}$ complexes in acetonitrile have a photochemical rather than thermal origin; iv) three different products are obtained in each case from acetonitrile solutions; v) both $\mathbf{3 C l}$ and $\mathbf{3 B r}$ are photostable when excited to their lowest MLCT state, irrespectively of the solvent.

The analysis of the IR spectra of the photolyzed acetonitrile solutions and the isolated crystal structure, which is shown in Figure 8, clearly points out that the main products are, in both the cases of $\mathbf{2} \mathbf{C l}$ and $\mathbf{2 B r}$, rhenium(I) dicarbonyl complexes with the two $\mathrm{CO}$ ligands 
arranged in cis configuration. This conclusion is established on observing that the three carbonyl peaks of the initial complexes turn into two sets each comprising two carbonyl peaks (Figure 7). Therefore, the photolysis of each initial tricarbonyl complex produces at least two distinct dicarbonyl complexes, one of which of formulation cis,cis$\left[\operatorname{Re}(\mathrm{CO})_{2}(\mathbf{P y} \operatorname{ImPh})\left(\mathrm{NCCH}_{3}\right) \mathrm{X}\right]$. The presence of this species corresponds to the signal at 8.77 ppm and two carbonyl bands at $1917,1831 \mathrm{~cm}^{-1}$ when the initial complex is $\mathbf{2 C l}$ and a signal at $8.78 \mathrm{ppm}$ and two carbonyl bands at $1918,1833 \mathrm{~cm}^{-1}$ for the photolysis of $\mathbf{2 B r}$. Further evidence confirming the loss of a carbonyl ligand from the rhenium centers are the facts that: i) the overall frequency of the carbonyl peaks decreases as expected by the removal of a strongly $\pi$-acidic ligand such as CO; ii) a bathochromic shift of the lowest MLCT state is revealed both in the absorption and emission spectra, as a consequence of the increased electron density on the metal center destabilizing the 5 d orbitals. ${ }^{41}$

The IR spectra also suggest the formation of a cationic tricarbonyl complex with a coordinated solvent molecule as in each case a band at $2036 \mathrm{~cm}^{-1}$ is present. The frequency of this band is analogous to that of the totally symmetric in phase $A^{\prime}(1)$ band of the acetonitrile solvato-complexes of formulation $f a c-\left[\operatorname{Re}(\mathrm{CO})_{3}(\operatorname{diim})\left(\mathrm{NCCH}_{3}\right)\right]^{+}{ }^{42,43}$ In order to verify this conclusion, we prepared the corresponding rhenium(I) tricarbonyl NHC solvato-complex, fac$\left[\operatorname{Re}(\mathrm{CO})_{3}(\mathbf{P y I m P h})\left(\mathrm{NCCD}_{3}\right)\right]^{+}$, by treating $\mathbf{2 C l}$ with 1 molar equivalent of $\mathrm{AgBF}_{4}$ in refluxing deuterated acetonitrile. ${ }^{44}$ As expected, its highest frequency carbonyl peak was found at $2035 \mathrm{~cm}^{-1}$. Furthermore, the ${ }^{1} \mathrm{H}-\mathrm{NMR}$ spectrum of fac$\left[\operatorname{Re}(\mathrm{CO})_{3}(\mathbf{P y} \operatorname{ImPh})\left(\mathrm{NCCD}_{3}\right)\right]^{+}$in deuterated acetonitrile showed a doublet corresponding to the H6 atom of the NHC ligand at $8.85 \mathrm{ppm}$, analogous to the same doublets found in the photolyzed ${ }^{1} \mathrm{H}-\mathrm{NMR}$ spectra of $\mathbf{2 C l}$ and $\mathbf{2 B r}$. A further conclusion that can be drawn, with this new experimental evidence, is that the photoexcitation of $\mathbf{2 C l}$ and $\mathbf{2 B r}$ favors the dissociation of the halogen ligand and the coordination of an acetonitrile molecule. The formation of the solvato-complex was not detected when an acetonitrile solution of either $\mathbf{2 C l}$ or $2 \mathrm{Br}$ was heated up to $70{ }^{\circ} \mathrm{C}$ in the dark. Moreover, the solvato-complex was not detected in heated or photolyzed acetone or chloroform solutions (see ESI).

We then attempted the photolysis of the deuterated acetonitrile solution of fac$\left[\operatorname{Re}(\mathrm{CO})_{3}(\mathbf{P y} \operatorname{ImPh})\left(\mathrm{NCCD}_{3}\right)\right]^{+}$(see ESI). Interestingly, this cationic complex was found to be photoactive, and the progression of the ${ }^{1} \mathrm{H}-\mathrm{NMR}$ spectrum showed the disappearance of the doublet at $8.85 \mathrm{ppm}$ and the appearance of an upfield doublet at $8.73 \mathrm{ppm}$, which is exactly the same as one of the doublets appearing from the photolysis of $\mathbf{2 C l}$ and $\mathbf{2 B r}$. Further photolysis of the cationic solvato-complex seems to yield a third product, which appears with 
a slightly deshielded doublet at $8.91 \mathrm{ppm}$. This product does not appear in the photolysis experiments of $\mathbf{2} \mathbf{C l}$ and $\mathbf{2 B r}$ and has not been identified yet. The IR spectrum of the photolyzed solution of $f a c-\left[\operatorname{Re}(\mathrm{CO})_{3}(\mathbf{P y I m P h})\left(\mathrm{NCCD}_{3}\right)\right]^{+}$displays two peaks at 1937,1862 $\mathrm{cm}^{-1}$, which are exactly the same peaks corresponding to one of the two dicarbonyl products in the photolysis of both $\mathbf{2 C l}$ and $\mathbf{2 B r}$. Therefore, taken together the data so far reveal that the excitation of $\mathbf{2 C l}$ and $\mathbf{2 B r}$ promotes the formation of the cationic acetonitrile-coordinated tricarbonyl complex that further photolyzes to yield the corresponding cationic dicarbonyl complex, for which the proposed formulation is $\left[\operatorname{Re}(\mathrm{CO})_{2}(\mathbf{P y} \operatorname{ImPh})\left(\mathrm{NCCD}_{3}\right)_{2}\right]^{+}$. Furthermore, the frequencies of the carbonyl bands of $\left[\operatorname{Re}(\mathrm{CO})_{2}(\mathbf{P y I m P h})\left(\mathrm{NCCD}_{3}\right)_{2}\right]^{+}$are higher than those of cis, cis- $\left[\operatorname{Re}(\mathrm{CO})_{2}(\mathbf{P y I m P h})\left(\mathrm{NCCD}_{3}\right) \mathrm{X}\right]$, in agreement with the positive charge of the former complex. The formulation proposed is based on the assumption that this species would undergo dissociation of the $\mathrm{CO}$ in trans to the NHC ligand. ${ }^{23}$

With all the photolysis products identified, the trend in the absorption and emission profiles shown in Figure 5 can be now explained. The initial MLCT band of both 2Cl and $\mathbf{2 B r}$ splits into a lower energy band associated to the lowest MLCT transition of the neutral complex cis,cis- $\left[\operatorname{Re}(\mathrm{CO})_{2}(\mathbf{P y} \mathbf{I m P h})\left(\mathrm{NCCH}_{3}\right) \mathrm{X}\right]$. On the other hand, the raising of a second MLCT process, blue-shifted with respect to the initial complexes, is attributed to the photochemical formation of the tricarbonyl solvato-complex fac$\left[\operatorname{Re}(\mathrm{CO})_{3}(\mathbf{P y} \operatorname{ImPh})\left(\mathrm{NCCH}_{3}\right)\right]^{+}$. This conclusion is further confirmed by noting that the absorption band for the MLCT transition of an acetonitrile solution of fac$\left[\operatorname{Re}(\mathrm{CO})_{3}(\mathbf{P y I m P h})\left(\mathrm{NCCH}_{3}\right)\right]^{+}$is centered at $320 \mathrm{~nm}$ (as a shoulder of the $\mathrm{LC}$ transition). The position of the MLCT of the third product, $\left[\operatorname{Re}(\mathrm{CO})_{2}(\mathbf{P y} \mathbf{I m P h})\left(\mathrm{NCCH}_{3}\right)_{2}\right]^{+}$, cannot be clearly established, however it should be located at higher energy than $\left[\operatorname{Re}(\mathrm{CO})_{2}(\mathbf{P y} \operatorname{ImPh})\left(\mathrm{NCCH}_{3}\right) \mathrm{X}\right]$, due to the positive charge, and at lower energy than fac$\left[\operatorname{Re}(\mathrm{CO})_{3}(\mathbf{P y} \operatorname{ImPh})\left(\mathrm{NCCH}_{3}\right)\right]^{+}$, due to the presence of only two CO ligands. In emission, only the red shifted bands of the dicarbonyl complexes are visible. These conclusions are supported by the fact that a solution of pure $f a c-\left[\operatorname{Re}(\mathrm{CO})_{3}(\mathbf{P y} \mathbf{I m P h})\left(\mathrm{NCCH}_{3}\right)\right]^{+}$in acetonitrile is colorless and non-emissive.

Our study so far has shown that the photochemical processes of $\mathbf{2 C l}$ and $\mathbf{2 B r}$ occur when the complexes are excited to their lowest excited state state, whose nature was previously assigned to ${ }^{3} \mathrm{MLCT}$, and originates from the presence of the NHC ligand. In fact, under the same conditions when irradiated at $365 \mathrm{~nm}$, a solution of $f a c-\left[\operatorname{Re}(\mathrm{CO})_{3}(\mathbf{p h e n}) \mathrm{Br}\right]$ in a deuterated acetonitrile solution was found to be photostable, in agreement with previously published results on the analogous chloro complex (see ESI). ${ }^{24,25}$ Based on all the results 
obtained with the characterization of the photolysis products, we propose the reaction pathway illustrated in Figure 9. The product cis, cis-[Re(CO) $\left.)_{2}(\mathbf{P y I m P h})\left(\mathrm{NCCH}_{3}\right) \mathrm{X}\right]$ is obtained by the direct $\mathrm{CO}$ substitution from the initial $\mathbf{2 C l}$ and $\mathbf{2 B r}$, as expected from a rhenium(I) tricarbonyl complex with a ligand possessing a strong trans effect. ${ }^{23}$ However it is not completely elucidated why its formation appears to be solvent-dependent, as no reaction is observed from acetone solutions of $\mathbf{2 C l}$ and $\mathbf{2 B r}$.

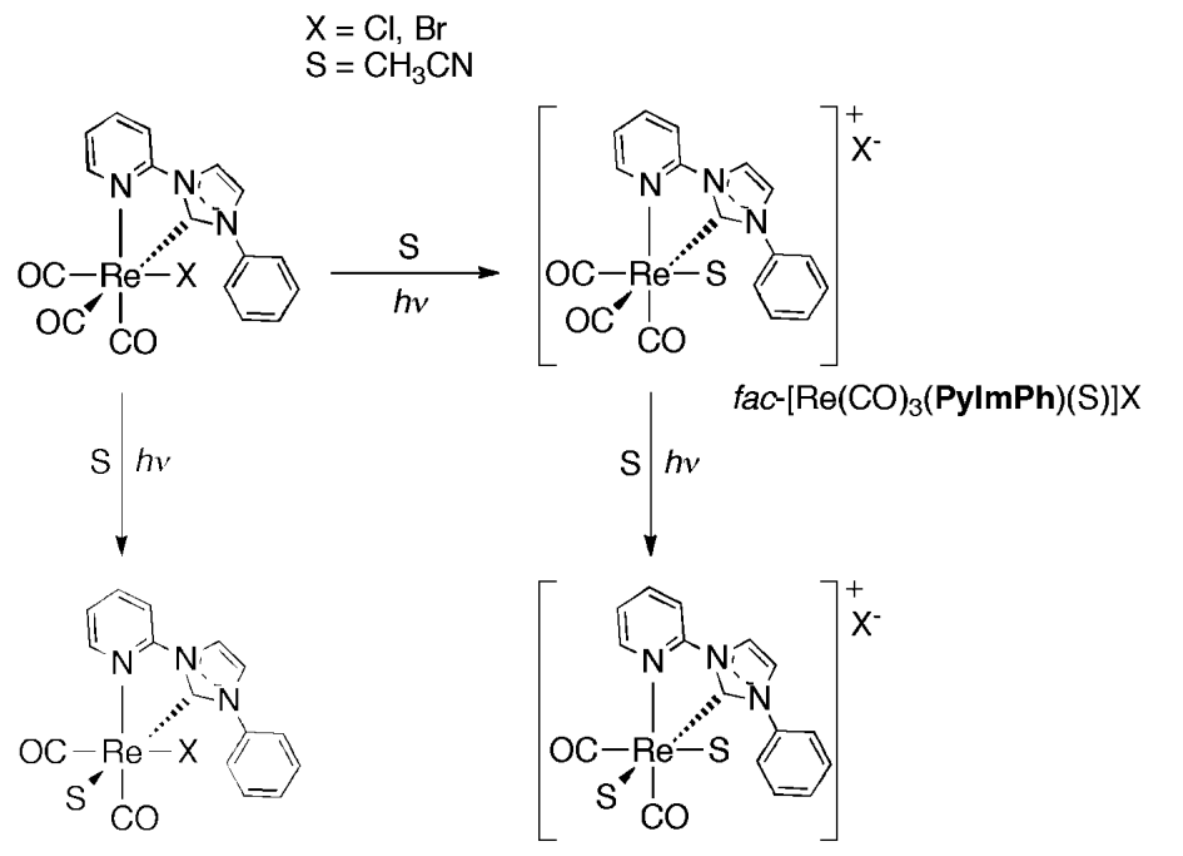

cis, cis- $\left[\operatorname{Re}(\mathrm{CO})_{2}(\mathrm{PylmPh})(\mathrm{S}) \mathrm{X}\right]$

cis, cis- $\left[\operatorname{Re}(\mathrm{CO})_{2}(\mathrm{PyImPh})(\mathrm{S})_{2}\right] \mathrm{X}$

Figure 9. Reaction pathway illustrating the photochemical transformations of $\mathbf{2 C l}$ and $\mathbf{2 B r}$ when excited to their lowest MLCT state at $\lambda_{\mathrm{ex}}=365 \mathrm{~nm}$.

Despite many attempts, we could not isolate and structurally characterize the disolvated cis,cis- $\left[\mathrm{Re}(\mathrm{CO})_{2}(\mathbf{P y} \mathbf{I m P h})\left(\mathrm{NCCH}_{3}\right)_{2}\right]$. In an effort to obtain more stable products, the photolysis of $\mathbf{2 B r}$ was carried out in the presence of a slight excess ( $c a .2 .5$ molar equivalents) of triethylphosphite in acetone, under the same experimental conditions described before. The choice of the acetone solvent was initially dictated to avoid complications with multiple reactions pathways, as in this solvent the formation of the solvato-complex was not detected in the previous experiments. The photolysis of an acetone solution of $\mathbf{2 B r}$ and triethylphosphite changed its pale yellow color to orange. After attempting the purification via column chromatography, a fraction containing two almost inseparable products was obtained and the co-crystallization of this mixture allowed us to identify the products as the two geometrical isomers cis,cis- and cis,trans- 
$\left[\operatorname{Re}(\mathrm{CO})_{2}(\mathbf{P y} \operatorname{ImPh})\left(\mathrm{P}(\mathrm{OEt})_{3}\right) \mathrm{Br}\right]$, whose structures are shown in Figure 10. The IR spectrum of this mixture produced two sets of signals, each containing two carbonyl peaks at 1927 , $1860 \mathrm{~cm}^{-1}$ and $1905,1838 \mathrm{~cm}^{-1}$, analogously to the IR spectra of the photolyzed $\mathbf{2 C l}$ and $\mathbf{2 B r}$.
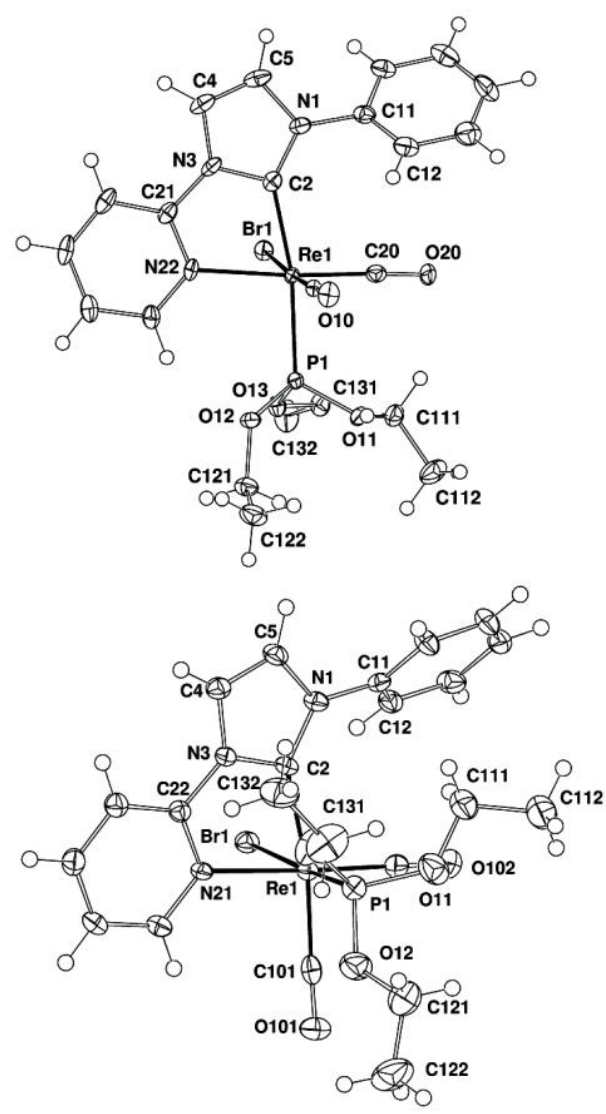

Figure 10. X-ray crystals structures of the cis,cis- (top) and cis,trans$\left[\operatorname{Re}(\mathrm{CO})_{2}(\mathbf{P y} \operatorname{ImPh})\left(\mathrm{P}(\mathrm{OEt})_{3}\right) \mathrm{Br}\right]$ (bottom) geometrical isomers, with ellipsoids drawn at the $50 \%$ probability level.

The cis,cis- $\left[\operatorname{Re}(\mathrm{CO})_{2}(\mathbf{P y I m P h})\left(\mathrm{P}(\mathrm{OEt})_{3}\right) \mathrm{Br}\right]$ is the complex expected by the substitution of one $\mathrm{CO}$ ligand trans to the $\mathrm{C}$ donor of the NHC ligand, analogous to the cis, cis- $\left[\operatorname{Re}(\mathrm{CO})_{2}(\mathbf{P y I m P h})\left(\mathrm{NCCH}_{3}\right) \mathrm{X}\right]$ previously observed (Figure 8$)$. On the other hand, the presence of the geometrical isomer cis,trans $-\left[\operatorname{Re}(\mathrm{CO})_{2}(\mathbf{P y} \mathbf{I m P h})\left(\mathrm{P}(\mathrm{OEt})_{3}\right) \mathrm{Br}\right]$ was justified following a multistep photochemical mechanism involving: i) the exchange of the halogen ligand for the phosphite ligand yielding $f a c-\left[\operatorname{Re}(\mathrm{CO})_{3}(\mathbf{P y} \operatorname{ImPh})\left(\mathrm{P}(\mathrm{OEt})_{3}\right)\right] \mathrm{Br}$; ii) the dissociation of the CO in trans to the phosphite ligand, which leaves a vacancy occupied by a molecule of solvent and eventually filled by the reconnection of the bromide ligand. This pathway is analogous to the bifurcated reactivity previously described by Sullivan for the complex $f a c-\left[\operatorname{Re}(\mathrm{CO})_{3}(\text { bipy })\left(\mathrm{P}(\mathrm{CCH})_{3}\right)\right]^{+}$, where $\mathrm{P}(\mathrm{CCH})_{3}$ is triethynylphosphine. ${ }^{18}$ No 
complex analogous to the previously observed cis, cis- $\left[\operatorname{Re}(\mathrm{CO})_{2}(\mathbf{P y} \mathbf{I m P h})\left(\mathrm{NCCH}_{3}\right)_{2}\right]^{+}$was observed, which is attributed to a more competitive $\mathrm{CO}$ labilization in trans to triethylphosphite rather than in trans to the NHC ligand. This mechanistic interpretation is formulated following the previsouly reported results ${ }^{23}$ that no geometrical rearrangement occurs on the octahedral complex or the square-pyramidal intermediates when the species in solution are excited to their lowest ${ }^{3}$ MLCT states.

A complete elucidation on the identity of the reactive excited state (or multiple reactive states considering that two distinct photochemical pathways have been demonstrated) is premature with the set of results presented in this work. The dissociation of the CO in trans to the labilizing NHC could be explained via thermal population of the ${ }^{3} \mathrm{LF}$ state from the lower lying ${ }^{3} \mathrm{MLCT}$, however the solvent dependency of this previously reported dissociative mechanism ${ }^{23}$ remains unanswered. Furthermore, the dissociation of the halogen ligand from $\mathbf{2 C l}$ and $2 \mathrm{Br}$ seems to be linked to the presence of the NHC ligand, as the analogous complexes bearing diimine ligands have not shown similar reactivity. The stability of the quinolinyl complexes $\mathbf{3 C l}$ and $\mathbf{3 B r}$ is certainly intriguing: the lack of reactivity in this case could be due to the fact that their ${ }^{3} \mathrm{MLCT}$ is lower in energy and therefore the increased energy gap does not allow thermal population of the ${ }^{3} \mathrm{LF}$ state; alternatively, if the reactive state is the ${ }^{3} \mathrm{MLCT}$, the lack of reactivity for $\mathbf{3 C l}$ and $\mathbf{3 B r}$ could be due to a strong LC character originating from the increased conjugation of the quinolinyl substituent.

\section{Conclusions}

This work reports the first photochemical investigation of tricarbonyl rhenium(I) NHC complexes. With the tools of this investigation being a mixture of synthetic chemistry, NMR, IR, UV-Vis absorption and emission spectroscopy as well as X-ray crystallography, it can be concluded that these complexes undergo photochemical $\mathrm{CO}$ dissociation after excitation to their lowest excited state. The photochemical transformations are therefore competing processing with radiative decays from the ${ }^{3}$ MLCT excited state. A mechanism invoking the dissociation of the $\mathrm{CO}$ in trans to the strongly $\sigma$-donating NHC moiety cannot completely explain the photoreactivity of the complexes. Clearly, the formation of the corresponding tricarbonyl solvato-complexes, by exchange of a solvent molecule with the halogen ligand, is a key step in the overall mechanism. The product of this exchange then undergoes further photochemical reactions to eventually yield the identified dicarbonyl products. While further investigation is warranted and it is in progress to completely elucidate the process and 
accurately determine photochemical quantum yields, the results in this report highlight fundamental characteristics of the relatively new class of rhenium(I) tricarbonyl complexes. So far being only investigated for their intrinsic luminescent properties, these species can now be further considered as building blocks in the synthesis of new phosphorescent dicarbonyl species, photocatalysis, and as photoactivated CO-releasing molecules for the treatment of inflammation-related pathologies. ${ }^{45,46}$

\section{Experimental section}

\section{General remarks}

All reagents and solvents were purchased from Sigma Aldrich and used as received without further purification. 1-Phenylimidazole was prepared according to a previously published procedure. ${ }^{47}$ THF was distilled over sodium/benzophenone according to general laboratory procedures. All procedures involving rhenium complexes were carried out under a nitrogen atmosphere using standard Schlenk techniques. Both the acidic and basic alumina for column chromatography were of Brockmann I activity unless otherwise specified. Alumina of Brockmann II activity was prepared by adding water to Brockmann I alumina at a ratio of $3 \%$ w/w, shaking until clumping stopped and left in a sealed container for two days. Nuclear magnetic resonance spectra were recorded using a Bruker Avance 400 spectrometer (400.1 $\mathrm{MHz}$ for ${ }^{1} \mathrm{H} ; 100 \mathrm{MHz}$ for ${ }^{13} \mathrm{C} ; 162 \mathrm{MHz}$ for ${ }^{31} \mathrm{P}$ ) at $300 \mathrm{~K} .{ }^{1} \mathrm{H}$ and ${ }^{13} \mathrm{C}$ NMR spectra were calibrated to residual solvent signals. ${ }^{31} \mathrm{P}$ NMR spectra were calibrated to an $85 \% \mathrm{H}_{3} \mathrm{PO}_{4}$ external standard. Infrared spectra were recorded using an attenuated total reflectance Perkin Elmer Spectrum 100 FT-IR with a diamond stage, either by using solid state samples or by drop casting a concentrated acetonitrile solution on the stage. IR spectra were recorded from 4000 to $650 \mathrm{~cm}^{-1}$. The intensities of the IR bands are reported as strong (s), medium (m), or weak (w), with broad (br) bands also specified. Melting points were determined using a BI Barnsted Electrothermal 9100 apparatus. Elemental analyses were obtained at the Central Science Laboratory, University of Tasmania, using a Thermo Finnigan EA 1112 Series Flash.

\section{Photophysical measurements}

Absorption spectra were recorded at room temperature using a Perkin Elmer Lambda $35 \mathrm{UV} / \mathrm{V}$ is spectrometer. Uncorrected steady state emission and excitation spectra were recorded on an Edinburgh FLSP920 spectrometer equipped with a 450 W Xenon arc lamp, 
double excitation and single emission monochromators and a peltier cooled Hamamatsu R928P photomultiplier tube (185-850 nm). Emission and excitation spectra were corrected for source intensity (lamp and grating) and emission spectral response (detector and grating) by a calibration curve supplied with the instrument. According to the approach described by Demas and Crosby, ${ }^{48}$ luminescence quantum yields $\left(\Phi_{\mathrm{em}}\right)$ were measured in optically dilute solutions (O.D. < 0.1 at excitation wavelength) obtained from absorption spectra on a wavelength scale $[\mathrm{nm}]$ and compared to the reference emitter by the following equation:

$$
{ }_{x}={ }_{r} \frac{A_{r}\left({ }_{r}\right)}{A_{x}\left({ }_{x}\right)} \frac{I_{r}\left({ }_{r}\right)}{I_{x}\left({ }_{x}\right)} \frac{n_{x}^{2}}{n_{r}^{2}} \frac{D_{x}}{D_{r}}
$$

where $A$ is the absorbance at the excitation wavelength $(\lambda), I$ is the intensity of the excitation light at the excitation wavelength $(\lambda), n$ is the refractive index of the solvent, $D$ is the integrated intensity of the luminescence and $\Phi$ is the quantum yield. The subscripts $r$ and $x$ refer to the reference and the sample, respectively. The quantum yield determinations were performed at identical excitation wavelength for the sample and the reference, therefore cancelling the $I\left(\lambda_{r}\right) / I\left(\lambda_{x}\right)$ term in the equation. All the Re complexes were measured against an air-equilibrated water solution of $\left[\mathrm{Ru}(\mathbf{b i p y})_{3}\right] \mathrm{Cl}_{2}$ used as reference $\left(\Phi_{r}=0.028\right) .{ }^{49}$ Emission lifetimes $(\tau)$ were determined with the single photon counting technique (TCSPC) with the same Edinburgh FLSP920 spectrometer using pulsed picosecond LEDs (EPLED 295 or EPLED 360, FHWM <800 ps) as the excitation source, with repetition rates between $10 \mathrm{kHz}$ and $1 \mathrm{MHz}$, and the above-mentioned R928P PMT as detector. The goodness of fit was assessed by minimizing the reduced $\chi^{2}$ function and by visual inspection of the weighted residuals. To record the $77 \mathrm{~K}$ luminescence spectra, the samples were put in glass tubes (2 mm diameter) and inserted in a special quartz Dewar filled up with liquid nitrogen. All the solvents used in the preparation of the solutions for the photophysical investigations were of spectrometric grade. All the prepared solutions were filtered through a $0.2 \mu \mathrm{m}$ syringe filter before measurement. Deaerated samples were prepared by the freeze-pump-thaw technique. Experimental uncertainties are estimated to be $\pm 8 \%$ for lifetime determinations, $\pm 20 \%$ for quantum yields, $\pm 2 \mathrm{~nm}$ and $\pm 5 \mathrm{~nm}$ for absorption and emission peaks, respectively. 


\section{Monitored photolysis}

Monitored photolysis experiments were carried out on a Hitachi F-7000 spectrofluorimeter. The reagents were added to acetonitrile in order to reach a final concentration of $c a \cdot 10^{-5} \mathrm{M}$ in a quartz cuvette. The solutions were irradiated at $\lambda_{\mathrm{ex}}=370 \mathrm{~nm}$ with an excitation slit set to $20 \mathrm{~nm}$ and emission slit to $5 \mathrm{~nm}$. A total of 99 consecutive spectra, with no delay between replicates, were run per solution at a speed of $240 \mathrm{~nm} / \mathrm{min}$ with the detector set to acquire a signal between 200 and $800 \mathrm{~nm}$. Under these experimental conditions, the solution was constantly irradiated for a period of approximately 4 hours. The spectra were recorded uncorrected for detector response.

\section{Lamp photolysis}

Lamp photolysis experiments were carried using a UVP Blak-Ray® B-100AP High Intensity UV Lamp with a $100 \mathrm{~W}$ bulb at a single wavelength output of $365 \mathrm{~nm}$. The experiments were performed in darkness. The reaction vessel consisted of either a glass NMR tube, containing a degassed deuterated solution of the complex, or a glass Schlenk tube containing a degassed and dry solution of the complex maintained under a nitrogen atmosphere. In each case, degassing was performed by bubbling a gentle stream of gaseous $\mathrm{N}_{2}$ for about 5 minutes via a Pasteur pipette immersed in the solution of the complex.

\section{Synthetic details}

Synthesis of 1-phenyl-3-(2-pyridyl)imidazolium chloride $(\mathrm{PyImPhH} \cdot \mathrm{Cl})$. A mixture of 2chloropyridine $(0.80 \mathrm{~mL}, 8.4 \mathrm{mmol})$ and 1-phenylimidazole $(210 \mathrm{mg}, 1.4 \mathrm{mmol})$ was heated in a sealed vessel at $170{ }^{\circ} \mathrm{C}$ for 3 days. The solution was cooled to room temperature, and purified by repetitive re-precipitation from dichloromethane-diethyl ether to afford a light brown solid $(0.10 \mathrm{~g}, 28 \%)$. M.p. $149-150{ }^{\circ} \mathrm{C}$. Anal. Calcd for $\left(\mathrm{C}_{14} \mathrm{H}_{12} \mathrm{ClN}_{3}\right) \cdot 1.5 \mathrm{H}_{2} \mathrm{O}: \mathrm{C}, 59.05$; H, 5.31; N, 14.76. Found: C, 58.84; H, 5.28; N, 14.86. ${ }^{1} \mathrm{H}$ NMR $\left(\mathrm{d}_{6}-\mathrm{DMSO}\right): \delta=10.79(1 \mathrm{H}$, s, imidazole $\mathrm{NCHN}), 8.77(1 \mathrm{H}$, app. t, splitting = 3.6 Hz, imidazole $\mathrm{CH}), 8.71(1 \mathrm{H}, \mathrm{d}, J=4.8$ $\mathrm{Hz}$, pyridyl H6), $8.61(1 \mathrm{H}$, app. t, splitting = 3.6 Hz, imidazole $\mathrm{CH}), 8.32-8.25(2 \mathrm{H}, \mathrm{m}$, pyridyl $H 5$; pyridyl $H 3), 8.00(2 \mathrm{H}, \mathrm{d}, J=5.4 \mathrm{~Hz}$, phenyl ortho- $H)$, 7.73-7.62 (4H, m, phenyl meta- $H$; phenyl para- $H$; pyridyl $H 4$ ) ppm. ${ }^{13} \mathrm{C}$ NMR (d ${ }_{6}$ DMSO): $\delta=149.7$ (pyridyl $C \mathrm{H}$ ), 146.8 (pyridyl quat. C), 141.1 (pyridyl $\mathrm{CH}$ ), 135.1 (phenyl quat. C), 134.8 (imidazole 
NCHN), 130.6 (pyridyl $C H$ ), 130.6 (phenyl $C H$ ), 125.9 (phenyl $C H$ ), 122.7 (imidazole $C H$ ), 122.6 (phenyl $C H$ ), 120.4(imidazole $C H$ ), 115.4 (pyridyl $C H$ ) ppm. IR: $v=3433$ s, $3371 \mathrm{~s}$, 3186 w, 3133 w, 3098 m, 3038 m, 3004 s, 1647 w, 1601 m, 1547 s, 1478 m, 1444 s, 1355 w, 1312 w, 1291 m, 1257 m, 1162 w, 1098 w, 1065 w, 997 w, 910 w, 780 w, 756 m, 720 w, 684 $\mathrm{W} \mathrm{cm}{ }^{-1}$.

Synthesis of 1-phenyl-3-(2-pyridyl)imidazolium bromide (PyImPhH·Br). A mixture of 2bromopyridine $(4.00 \mathrm{~mL}, 42.0 \mathrm{mmol})$ and 1-phenylimidazole $(1.00 \mathrm{~g}, 7.0 \mathrm{mmol})$ was heated in a sealed vessel at $170{ }^{\circ} \mathrm{C}$ for 3 days. The solution was cooled to room temperature, and purified by repetitive re-precipitation from dichloromethane-diethyl ether to afford a dark brown solid (1.66 g, 69\%). M.p. 222-223 ${ }^{\circ} \mathrm{C}$. Anal. Calcd for $\left(\mathrm{C}_{14} \mathrm{H}_{12} \mathrm{BrN}_{3}\right) \cdot 0.5 \mathrm{CH}_{2} \mathrm{Cl}_{2}: \mathrm{C}$, 50.53; H, 3.80; N, 12.19. Found C, 50.45; H, 3.69; N, 12.14. ${ }^{1} \mathrm{H}$ NMR ( $\left.{ }_{6}-\mathrm{DMSO}\right): \delta=10.59$ $(1 \mathrm{H}$, s, imidazole $\mathrm{NCHN}), 8.75(1 \mathrm{H}$, app. t, splitting $=3.6 \mathrm{~Hz}$, imidazole $\mathrm{CH}), 8.71(1 \mathrm{H}, \mathrm{d}, J$ $=4.8 \mathrm{~Hz}$, pyridyl H6), $8.57(1 \mathrm{H}$, app. t, splitting = 4.0 Hz, imidazole $\mathrm{CH}), 8.30-8.26(1 \mathrm{H}, \mathrm{m}$, pyridyl H5), $8.16(1 \mathrm{H}, \mathrm{d}, J=8.4 \mathrm{~Hz}$, pyridyl $H 3), 7.94(2 \mathrm{H}, \mathrm{d}, J=7.2 \mathrm{~Hz}$, phenyl ortho- $H)$, 7.74-7.63 (4H, m, phenyl meta- $H$; phenyl para- $H$; pyridyl $H 4)$ ppm. ${ }^{13} \mathrm{C}$ NMR (d 6 -DMSO): $\delta$ = 149.3 (pyridyl $C H$ ), 146.3 (pyridyl quat. $C$ ), 140.6 (pyridyl $C H$ ), 134.7 (phenyl quat. $C$ ), 134.3 (imidazole $\mathrm{NCHN}$ ), 130.2 (pyridyl $\mathrm{CH}$; phenyl $\mathrm{CH}$ ), 125.5 (phenyl $\mathrm{CH}$ ), 122.3 (imidazole $C H$; phenyl $C H$ ), 120.0 (imidazole $C H$ ), 114.8 (pyridyl $C H$ ) ppm. IR: $v=3192 \mathrm{~m}$, 3089 m, 3040 m, 2984 s, 1616 w, 1597 s, 1538 s, 1477 s, 1467 w, 1440 s, 1396 w, 1349 w, 1306 w, 1247 m, 1248 m, 1153 w, 1098 w, 1083 w, 1052 w, 993 w, 951 w, 906 w, 865 w, $793 \mathrm{w}, 757 \mathrm{~s}, 717 \mathrm{w}, 681 \mathrm{~m} \mathrm{~cm}^{-1}$.

Synthesis of 1-phenyl-3-(quinolin-2-yl)imidazolium chloride (QiImPhH·Cl). A mixture of 2-chloroquinoline (600 mg, $3.7 \mathrm{mmol})$ and 1-phenylimidazole (500 mg, $3.5 \mathrm{mmol}$ ) was heated in a sealed vessel at $170{ }^{\circ} \mathrm{C}$ for 24 hours. The mixture was cooled to room temperature and purified by repetitive re-precipitation from dichloromethane-tetrahydrofuran to afford a light brown solid (470 mg, $44 \%$ ). M.p. 203-204 ${ }^{\circ} \mathrm{C}$. Anal. Calcd for $\left(\mathrm{C}_{18} \mathrm{H}_{14} \mathrm{ClN}_{3}\right) \cdot 1.6 \mathrm{H}_{2} \mathrm{O}$ : $\mathrm{C}, 64.23 ; \mathrm{H}, 5.15 ; \mathrm{N}, 12.49$. Found $\mathrm{C}, 64.16 ; \mathrm{H}, 4.87 ; \mathrm{N}, 12.48 .{ }^{1} \mathrm{H}$ NMR $\left(\mathrm{d}_{6}-\mathrm{DMSO}\right): \delta=$ $10.87(1 \mathrm{H}, \mathrm{s}$, imidazole $\mathrm{NCHN}), 8.93(1 \mathrm{H}$, app. t, splitting $=4.0 \mathrm{~Hz}$, imidazole $\mathrm{CH}), 8.89$ $(1 \mathrm{H}, \mathrm{d}, J=8.8 \mathrm{~Hz}$, quinolinyl $\mathrm{CH}), 8.67(1 \mathrm{H}$, app. t, splitting $=4.0 \mathrm{~Hz}$, imidazole $\mathrm{CH}), 8.39$ $(1 \mathrm{H}, \mathrm{d}, J=8.8 \mathrm{~Hz}$, quinolinyl $\mathrm{CH}), 8.19(1 \mathrm{H}, \mathrm{d}, J=7.6 \mathrm{~Hz}$, quinolinyl $\mathrm{CH}), 8.14(1 \mathrm{H}, \mathrm{d}, J=$ 8.4 Hz, quinolinyl $\mathrm{CH}), 8.03-7.95$ (3H, m, phenyl ortho- $H$; quinolinyl $\mathrm{CH}), 7.81-7.66(4 \mathrm{H}, \mathrm{m}$, 
phenyl meta- $H$; phenyl para- $H$; quinolinyl $\mathrm{C} H$ ) ppm. ${ }^{13} \mathrm{C}$ NMR $\left(\mathrm{d}_{6}-\mathrm{DMSO}\right): \delta=145.5$ (quinolinyl quat. $C$ ), 145.2 (quinolinyl quat. C), 141.3 (quinolinyl $\mathrm{CH}$ ), 134.9 (imidazole $\mathrm{NCHN}$ ), 134.6 (quinolinyl quat. $C$ ), 131.8 (quinolinyl $C H$ ), 130.2 (phenyl $C H$ ), 130.1 (phenyl $\mathrm{CH}$ ), 128.4 (quinolinyl $\mathrm{CH}$ ), 128.3 (quinolinyl $\mathrm{CH}$ ), 128.1 (phenyl quat. $C$ ), 127.9 (quinolinyl $C \mathrm{H}$ ), 122.3 (imidazole $C \mathrm{H}$ ), 122.2 (phenyl $C \mathrm{H}$ ), 120.0 (imidazole $C \mathrm{H}$ ), 113.0 (quinolinyl $C \mathrm{H}$ ) ppm. IR: $v=3341 \mathrm{~s}, 3091 \mathrm{~m}, 3037 \mathrm{w}, 2959 \mathrm{~m}, 2825 \mathrm{w}, 2161 \mathrm{w}, 1646 \mathrm{w}, 1617 \mathrm{w}, 1594 \mathrm{w}$, 1580 w, 1547 m, 1501 m, 1463 w, 1434 w, 1390 w, 1309 w, 1292 w, 1283 w, 1267 w, 1255 w, 1239 w, 1201 w, 1133 w, 1118 w, 1066 w, 991 w, 934 w, 915 w, 871 w, 827 w, 779 w, $762 \mathrm{w}, 753 \mathrm{w}, 685 \mathrm{w} \mathrm{cm}^{-1}$.

Synthesis of 2Cl. A mixture of PyImPhH.Cl (80 mg, $0.3 \mathrm{mmol}$ ), triethylamine (405 $\mu \mathrm{L}, 3.0$ $\mathrm{mmol})$ and pentacarbonylchlororhenium(I) $(100 \mathrm{mg}, 0.3 \mathrm{mmol})$ in toluene $(5 \mathrm{~mL})$ was degassed by a freeze-pump-thaw cycle and heated at reflux for 3 days. The mixture was cooled to room temperature and water $(5 \mathrm{~mL})$ and hexanes $(5 \mathrm{~mL})$ was added. The resulting brown solid was collected and purified by elution through a short plug of deactivated acidic alumina with dichloromethane $(100 \mathrm{~mL})$. The yellow filtrate was concentrated in vacuo and the residue was washed with hexanes $(20 \mathrm{~mL})$ to afford a yellow solid (60 mg, 37\%). Crystals suitable for a single crystal X-ray diffraction study were grown from slow evaporation of an acetonitrile solution. M.p. $243{ }^{\circ} \mathrm{C}$ (dec.). Anal. Calcd for $\mathrm{C}_{17} \mathrm{H}_{11} \mathrm{ClN}_{3} \mathrm{O}_{3} \mathrm{Re}$ : C, 38.71; H, 1.96; $\mathrm{N}, 7.81$. Found C, 38.75; H, 2.10; N, 7.98. ${ }^{1} \mathrm{H}$ NMR (d $\left.\mathrm{d}_{6}-\mathrm{DMSO}\right): \delta=8.88(1 \mathrm{H}, \mathrm{d}, J=5.2 \mathrm{~Hz}$, pyridyl H6), $8.69(1 \mathrm{H}, \mathrm{d}, J=2.0 \mathrm{~Hz}$, imidazole $\mathrm{CH}), 8.39-8.37(2 \mathrm{H}, \mathrm{m}, 2$ x pyridyl $\mathrm{CH}), 8.00$ $(1 \mathrm{H}, \mathrm{d}, J=2.0 \mathrm{~Hz}$, imidazole $\mathrm{CH}), 7.71-7.55(6 \mathrm{H}, \mathrm{m}, 5 \mathrm{x}$ phenyl $\mathrm{CH}$; pyridyl $\mathrm{CH}) \mathrm{ppm} .{ }^{13} \mathrm{C}$ NMR (d ${ }_{6}$-DMSO): $\delta=197.9(C O), 196.8(C O), 190.9(\mathrm{NCN}), 189.2(C O), 153.3$ (pyridyl $C \mathrm{H}$ ), 152.7 (pyridyl quat. $C$ ), 142.3 (pyridyl $C \mathrm{H}$ ), 139.1 (phenyl quat. $C$ ), 129.6 (phenyl $C \mathrm{H}$ ), 129.4 (phenyl $C H$ ), 126.1 (phenyl $C H$ ), 125.1 (imidazole $C H$ ), 124.3 (pyridyl $C H$ ), 118.1 (imidazole $C \mathrm{H}$ ), 113.2 (pyridyl $C \mathrm{H}$ ) ppm. IR: $v=3904 \mathrm{w}, 3782 \mathrm{w}, 3167 \mathrm{~m}, 3123 \mathrm{~m}, 3100 \mathrm{~m}$, $2010 \mathrm{~s}$ (CO), $1921 \mathrm{~s}$ (CO), $1890 \mathrm{~s}$ (CO), 1613 m, 1595 m, 1578 m, 1485 s, 1456 m, 1424 m, 1385 w, 1345 m, 1324 m, 1309 m, 1294 m, 1272 m, 1175 w, 1161 w, 1136 w, 1094 w, 1076 w, 1028 w, 990 w, 964 w, 948 w, 929 w, 882 w, 780 m, 765 m, 749 m, 736 w, 700 m, 692 m $\mathrm{cm}^{-1}$. IR (acetonitrile solution): $v=2018(\mathrm{CO}), 1926(\mathrm{CO}), 1899(\mathrm{CO}) \mathrm{cm}^{-1}$

Synthesis of 2Br. A mixture of PyImPhH·Br ( $83 \mathrm{mg}, 0.3 \mathrm{mmol}$ ), triethylamine (385 $\mu \mathrm{L}, 2.8$ $\mathrm{mmol})$ and pentacarbonylbromorhenium(I) $(110 \mathrm{mg}, 0.3 \mathrm{mmol})$ in toluene $(5 \mathrm{~mL})$ was degassed by a freeze-pump-thaw cycle and heated at reflux for 3 days. The mixture was 
cooled to room temperature and water $(5 \mathrm{~mL})$ and hexanes $(5 \mathrm{~mL})$ was added. The resulting brown solid was collected and purified by elution through a short plug of deactivated acidic alumina with dichloromethane $(100 \mathrm{~mL})$. The yellow filtrate was concentrated in vacuo and the residue was washed with hexanes $(20 \mathrm{~mL})$ to afford a yellow solid $(100 \mathrm{mg}, 70 \%)$. Crystals suitable for a single crystal X-ray diffraction study were grown from slow evaporation of an acetonitrile solution. M.p. $255^{\circ} \mathrm{C}$ (dec). Anal. Calcd for $\mathrm{C}_{17} \mathrm{H}_{11} \mathrm{BrN}_{3} \mathrm{O}_{3} \mathrm{Re}$ : $\mathrm{C}, 35.73 ; \mathrm{H}, 1.94 ; \mathrm{N}, 7.36$. Found $\mathrm{C}, 35.73 ; \mathrm{H}, 1.83 ; \mathrm{N}, 7.25 .{ }^{1} \mathrm{H}$ NMR $\left(\mathrm{d}_{6}-\mathrm{DMSO}\right): \delta=8.88$ $(1 \mathrm{H}, \mathrm{d}, J=4.4 \mathrm{~Hz}$, pyridyl $H 6), 8.70(1 \mathrm{H}, \mathrm{d}, J=2.4 \mathrm{~Hz}$, imidazole $\mathrm{CH}), 8.38-8.34(2 \mathrm{H}, \mathrm{m}, 2 \mathrm{x}$ pyridyl $\mathrm{CH}), 8.00(1 \mathrm{H}, \mathrm{d}, J=2.4 \mathrm{~Hz}$, imidazole $\mathrm{CH}), 7.71-7.53(6 \mathrm{H}, \mathrm{m}, 5 \mathrm{x}$ phenyl $\mathrm{CH}$; pyridyl CH) ppm. ${ }^{13} \mathrm{C}$ NMR (d d $_{6}$ DMSO): $\delta=197.3(\mathrm{CO}), 196.2(\mathrm{CO}), 190.0(\mathrm{NCN}), 188.7$ (CO), 153.5 (pyridyl $C H$ ), 152.6 (pyridyl quat. $C$ ), 142.2 (pyridyl $C H$ ), 139.1 (phenyl quat. C), 129.6 (phenyl $C H$ ), 129.4 (phenyl $C H$ ), 126.1 (phenyl $C H$ ), 125.2 (imidazole $C H$ ), 124.2 (pyridyl $\mathrm{CH}$ ), 118.1 (imidazole $\mathrm{CH}$ ), 113.2 (pyridyl $\mathrm{CH}$ ) ppm. IR: $v=3906 \mathrm{w}, 3785 \mathrm{w}, 3167$ w, 3123 m, 3101 m, 2010 s (CO), 1923 s (CO), 1894 s (CO), 1614 m, 1595 m, 1578 m, 1485 s, $1456 \mathrm{~m}, 1423 \mathrm{~m}, 1383 \mathrm{~m}, 1344 \mathrm{~m}, 1324 \mathrm{~m}, 1308$ m, 1293 m, 1272 m, 1175 w, $1161 \mathrm{~m}$, 1136 m, 1123 w, 1093 m, 1076 m, 1028 w, 989 w, 963 w, 948 w, 929 w, 880 w, 779 m, 765 m, $747 \mathrm{~m}, 735 \mathrm{w}, 700 \mathrm{~m}, 691 \mathrm{~m} \mathrm{~cm}^{-1}$. IR (acetonitrile solution) $v=2016$ (CO), 1922 (CO), $1893(\mathrm{CO}) \mathrm{cm}^{-1}$.

Synthesis of 3Cl. A mixture of pentacarbonylchlororhenium(I) (120 mg, $0.3 \mathrm{mmol}$ ), QiImPhH.Cl (100 mg, $0.3 \mathrm{mmol})$ and triethylamine $(445 \mu \mathrm{L}, 3.2 \mathrm{mmol})$ in toluene $(15 \mathrm{~mL})$ was heated to reflux for 4 days under a nitrogen atmosphere. The reaction mixture was cooled to room temperature and acetonitrile $(20 \mathrm{~mL})$ and hexanes were added $(20 \mathrm{~mL})$. The polar phase was collected, concentrated in vacuo and purified by filtration through a short plug of deactivated acidic alumina using dichloromethane. The solvent was removed under reduced pressure to afford a dark yellow solid (40 mg, $21 \%$ ). Crystals suitable for a single crystal Xray diffraction study were grown from slow evaporation of an acetonitrile solution. M.p. 290 ${ }^{\circ} \mathrm{C}$ (dec). Anal. Calcd for $\mathrm{C}_{21} \mathrm{H}_{13} \mathrm{ClN}_{3} \mathrm{O}_{3} \mathrm{Re}$ : C, 43.71; H, 2.27; N, 7.28. Found C, 43.50; H, 2.06; N, 6.97. ${ }^{1} \mathrm{H}$ NMR ( $\left.\mathrm{d}_{6}-\mathrm{DMSO}\right): \delta=9.01(1 \mathrm{H}, \mathrm{d}, J=8.8 \mathrm{~Hz}$, quinolinyl $\mathrm{CH}), 8.40(1 \mathrm{H}, \mathrm{d}$, $J=2.0 \mathrm{~Hz}$, imidazole $\mathrm{CH}), 8.61(1 \mathrm{H}, \mathrm{d}, J=8.0 \mathrm{~Hz}$, quinolinyl $\mathrm{CH}), 8.53(1 \mathrm{H}, \mathrm{d}, J=8.8 \mathrm{~Hz}$, quinolinyl $\mathrm{CH}), 8.23(1 \mathrm{H}, \mathrm{d}, J=8.0 \mathrm{~Hz}$, quinolinyl $\mathrm{CH}), 8.10(1 \mathrm{H}, \mathrm{dd}, J(1)=7.6 \mathrm{~Hz}, J(2)=$ $8.0 \mathrm{~Hz}$, quinolinyl $\mathrm{CH}), 7.85(1 \mathrm{H}, \mathrm{d}, J=2.4 \mathrm{~Hz}$, imidazole $\mathrm{CH}), 7.83(1 \mathrm{H}, \mathrm{dd}, J(1)=7.2 \mathrm{~Hz}$, $J(2)=7.8 \mathrm{~Hz}$, quinolinyl $\mathrm{CH}), 7.73-7.63(5 \mathrm{H}, \mathrm{m}$, phenyl $\mathrm{C} H) \mathrm{ppm} .{ }^{13} \mathrm{C} \mathrm{NMR}\left(\mathrm{d}_{6}-\mathrm{DMSO}\right): \delta=$ $198.4(C O), 195.2(C O), 192.8(\mathrm{NCN}), 189.5(C O), 154.2$ (quinolinyl quat. $C$ ), 145.5 
(quinolinyl quat. $\mathrm{C}$ ), 143.7 (quinolinyl $\mathrm{CH}$ ), 139.1 (quinolinyl quat. $\mathrm{C}$ ), 132.9 (quinolinyl $\mathrm{CH}$ ), 129.7 (phenyl $\mathrm{CH}$ ), 129.6 (phenyl $\mathrm{CH}$ ), 129.4 (quinolinyl $\mathrm{CH}$ ), 128.7 (quinolinyl $\mathrm{CH}$ ), 127.7 (phenyl quat. $C$ ), 126.8 (quinolinyl $C H$ ), 126.2 (phenyl $C H$ ), 125.4 (imidazole $C H$ ), 118.9 (imidazole $C H$ ), 112.0 (quinolinyl $C H$ ) ppm. IR: $v=3097$ w, $2010 \mathrm{~s}(\mathrm{CO}), 1910$ (CO) s, $1876(\mathrm{CO}) \mathrm{s}, 1852(\mathrm{CO}) \mathrm{s}, 1599 \mathrm{~m}, 1513 \mathrm{~m}, 1499 \mathrm{~m}, 1474 \mathrm{w}, 1428 \mathrm{~m}, 1371 \mathrm{w}, 1331 \mathrm{~m}$, 1310 w, 1276 w, 1251 w, 1168 w, 1149 w, 1108 m, 1099 w, 990 w, 961 w, 944 w, 865 w, 844 w, $821 \mathrm{~m}, 773 \mathrm{~m}, 749 \mathrm{~s}, 696 \mathrm{~s}, 677 \mathrm{~m} \mathrm{~cm}^{-1}$.

Synthesis of $3 \mathbf{B r}$. A saturated aqueous solution of $\mathrm{KPF}_{6}$ was added to an aqueous solution of QiImPhH·Cl until no further precipitation occurred. The light brown solid was collected dried and used without further purification. A mixture of pentacarbonylbromorhenium(I) (50 $\mathrm{mg}, 0.1 \mathrm{mmol})$, QiImPhH$\cdot \mathrm{PF}_{6}(50 \mathrm{mg}, 0.1 \mathrm{mmol})$ and triethylamine $(445 \mu \mathrm{L}, 3.2 \mathrm{mmol})$ in toluene $(15 \mathrm{~mL})$ was heated to reflux for 48 hours. The reaction mixture was cooled to room temperature and acetonitrile $(20 \mathrm{~mL})$ and hexanes were added $(20 \mathrm{~mL})$. The polar phase was collected and the solvent was removed under reduced pressure and purified by elution through a short plug of deactivated acidic alumina using dichloromethane. The solvent was removed in vacuo to afford a yellow solid (30 mg, 48\%). Crystals suitable for a single crystal X-ray diffraction study were grown from slow evaporation of an acetonitrile solution. M.p. $295^{\circ} \mathrm{C}$ (dec). Anal. Calcd for $\mathrm{C}_{21} \mathrm{H}_{13} \mathrm{BrN}_{3} \mathrm{O}_{3}$ Re: $\mathrm{C}$, 40.50; H, 2.09; N, 6.76. Found C, 40.47; H, 1.91; $\mathrm{N}, 6.55 .{ }^{1} \mathrm{H}$ NMR $\left(\mathrm{d}_{6}-\mathrm{DMSO}\right): \delta=9.00(1 \mathrm{H}, \mathrm{d}, J=8.8 \mathrm{~Hz}$, quinolinyl $\mathrm{CH}), 8.85(1 \mathrm{H}, \mathrm{d}, J=$ $2.0 \mathrm{~Hz}$, imidazole $\mathrm{CH}), 8.60(1 \mathrm{H}, \mathrm{d}, J=8.8 \mathrm{~Hz}$, quinolinyl $\mathrm{CH}), 8.53(1 \mathrm{H}, \mathrm{d}, J=8.8 \mathrm{~Hz}$, quinolinyl $\mathrm{CH}), 8.23(1 \mathrm{H}, \mathrm{d}, J=8.0 \mathrm{~Hz}$, quinolinyl $\mathrm{CH}), 8.10(1 \mathrm{H}, \mathrm{dd}, J(1)=7.6 \mathrm{~Hz}, J(2)=$ $8.0 \mathrm{~Hz}$, quinolinyl $\mathrm{CH}), 8.06(1 \mathrm{H}, \mathrm{d}, J=2.0 \mathrm{~Hz}$, imidazole $\mathrm{CH}), 7.83(1 \mathrm{H}, \mathrm{dd}, J(1)=7.6 \mathrm{~Hz}$, $J(2)=7.8 \mathrm{~Hz}$, quinolinyl $\mathrm{CH}), 7.73-7.64(5 \mathrm{H}, \mathrm{m}$, phenyl $\mathrm{CH}) \mathrm{ppm} .{ }^{13} \mathrm{C} \mathrm{NMR}\left(\mathrm{d}_{6}-\mathrm{DMSO}\right): \delta=$ 197.7 (CO), $194.6(C \mathrm{O}), 191.8(\mathrm{NCN}), 188.9$ (CO), 154.3 (quinolinyl quat. $C$ ), 145.7 (quinolinyl quat. $C$ ), 143.6 (quinolinyl $\mathrm{CH}$ ), 139.1 (quinolinyl quat. $C$ ), 132.8 (quinolinyl $C \mathrm{H}$ ), 129.7 (phenyl $C \mathrm{H}$ ), 129.6 (phenyl $\mathrm{CH}$ ), 129.5 (quinolinyl $\mathrm{CH}$ ) 128.8 (quinolinyl $C \mathrm{H}$ ), 127.7 (phenyl quat. $C$ ), 126.8 (quinolinyl $C H$ ), 126.3 (phenyl $C H$ ), 125.6 (imidazole $C H$ ), 118.9 (imidazole $C H$ ), 112.0 (quinolinyl $C H$ ) ppm. IR: $v=3169$ m, 3097 m, 2011 s (CO), 1912 s (CO), 1880 s (CO), 1857 s (CO), 3169 w, 3097 w, 1616 w, 1599 w, 1514 w, 1499 w, 1474 w, 1427 w, 1393 w, 1371 w, 1332 w, 1309 w, 1276 w, 1250 w, 1214 w, 1168 w, 1149 w, 1122 w, 1027 w, 991 w, 961 w, 944 w, 864 w, 821 w, 778 w, 745 w, $695 \mathrm{w} \mathrm{cm}^{-1}$. 
Preparation of cis,cis- and cis,trans-[Re(CO) $\left.)_{2}(\mathrm{PyImPh})\left(\mathrm{P}(\mathrm{OEt})_{3}\right) \mathrm{Br}\right]$ geometrical isomers. A light yellow solution of $\mathbf{2 B r}(4.6 \mathrm{mg}, 0.01 \mathrm{mmol})$ and triethylphosphite $(3 \mu \mathrm{L}, 0.03 \mathrm{mmol})$ in acetone $(2 \mathrm{~mL})$ was irradiated with UV light $(365 \mathrm{~nm})$ for 3 hours whilst being vigorously stirred. The resulting dark orange solution was left undisturbed to slowly evaporate and formed a mixture of yellow and orange crystals amidst some yellow amorphous solid. The crystals were separated by hand-picking and the yellow crystals were determined to the be cis, cis- $\left[\operatorname{Re}(\mathrm{CO})_{2}(\mathbf{P y I m P h})\left(\mathrm{P}(\mathrm{OEt})_{3}\right) \mathrm{Br}\right]$ whilst the orange were determined to the be cis,trans$\left[\operatorname{Re}(\mathrm{CO})_{2}(\mathbf{P y} \operatorname{ImPh})\left(\mathrm{P}(\mathrm{OEt})_{3}\right) \mathrm{Br}\right]$. The IR spectrum indicated evidence of starting material still present. IR (from acetone solution): $v=2016 \mathrm{~m}(\mathrm{CO}), 1927 \mathrm{~s}(\mathrm{CO}), 1905 \mathrm{~s}(\mathrm{CO}), 1860 \mathrm{~s}$ (CO), $1838 \mathrm{~s}(\mathrm{CO}) \mathrm{cm}^{-1}$. In an attempt to isolate a pure product, a light yellow solution of $\mathbf{2 C l}$ $(47.3 \mathrm{mg}, 0.08 \mathrm{mmol})$ and triethylphosphite $(36 \mu \mathrm{L}, 0.20 \mathrm{mmol})$ in acetone $(15 \mathrm{~mL})$ was irradiated with UV light $(365 \mathrm{~nm})$ for 5.5 hours while being vigorously stirred. The resulting dark orange solution was concentrated in vacuo and separated via column chromatography on deactivated alumina. The first four fractions were eluted by gradually increasing the polarity of the eluent, from pure diethyl ether to pure ethyl acetate, and contained several unidentified species. IR data suggested the presence of starting $\mathbf{2 C l}$ in these fractions. The fifth fraction was eluted with pure acetonitrile and was further purified with a second column, again on deactivated alumina as stationary phase, using ethyl acetate as eluent. The combined fractions were concentrated in vacuo to afford a yellow powder $(5 \mathrm{mg}, 8 \%)$. Anal. Calcd for $\left(\mathrm{C}_{22} \mathrm{H}_{26} \mathrm{ClN}_{3} \mathrm{O}_{5} \mathrm{PRe}\right) \cdot 2 \mathrm{CH}_{3} \mathrm{CO}_{2} \mathrm{CH}_{2} \mathrm{CH}_{3}$ : C, 42.83; H, 5.03; N, 4.99. Found: C, 42.83; H, 4.97; $\mathrm{N}, 5.04 . .{ }^{1} \mathrm{H}$ NMR ( $\mathrm{d}_{6}$-acetone): $\delta=8.93(1 \mathrm{H}, \mathrm{d}, J=5.6 \mathrm{~Hz}$, pyridyl $H 6), 8.37(1 \mathrm{H}, \mathrm{d}, J=2.4$ $\mathrm{Hz}$, imidazole $\mathrm{CH}), 8.22-8.17(1 \mathrm{H}, \mathrm{dd}, J(1)=8.4 \mathrm{~Hz}, J(2)=7.2 \mathrm{~Hz}$, pyridyl $H 4), 8.13-8.11$ (1H, m, pyridyl H3), 8.10-8.03 (2H, m, phenyl ortho- $H), 7.71(1 \mathrm{H}, \mathrm{d}, J=2.4 \mathrm{~Hz}$, imidazole $\mathrm{CH})$, 7.60-7.44 (4H, m, phenyl meta- $H$; phenyl para- $H$; pyridyl $H 5)$ ppm. The NMR spectrum also showed the presence of ethyl acetate in a ratio consistent with the obtained elemental analysis. ${ }^{31} \mathrm{P}\left\{{ }^{1} \mathrm{H}\right\}-\mathrm{NMR}$ ( $\mathrm{d}_{6}$-acetone): $\delta=123.2 \mathrm{ppm}$. A complete ${ }^{13} \mathrm{C}-\mathrm{NMR}$ could not be obtained due to the low concentration of the solution.

\section{X-ray crystallographical data}

Crystallographic data for the structures were collected at 100(2) K on either an Oxford Diffraction Xcalibur or Gemini diffractometer fitted with Mo $\mathrm{K} \alpha$ radiation. Following analytical absorption corrections and solution by direct methods, the structure was refined against $F^{2}$ with full-matrix least-squares using the program SHELXL-97. ${ }^{50}$ All hydrogen 
atoms were added at calculated positions and refined by use of a riding model with isotropic displacement parameters based on those of the parent atoms.

Crystal data for 2 Cl. Empirical formula $\mathrm{C}_{17} \mathrm{H}_{11} \mathrm{ClN}_{3} \mathrm{O}_{3} \mathrm{Re} ; M W=526.94$. Monoclinic, Space group $P 2_{1} / n, a=11.55800(10), b=8.39400(10), c=16.9605(2) \AA, \beta=96.2870(10)^{\circ}$, Volume $=1635.57(3) \AA^{3}, Z=4 ; \rho_{c}=2.140 \mathrm{Mg} / \mathrm{m}^{3}, \mu=7.615 \mathrm{~mm}^{-1}$, crystal size $0.46 \times 0.15 \mathrm{x}$ $0.056 \mathrm{~mm}^{3} ; \theta_{\min , \max }=3.86,45.71^{\circ}$. Reflections collected $=96088$, unique reflections $=13943$ $[R($ int $)=0.0389]$. Max. and min. transmission $=0.656$ and 0.128 . Number of parameters $=$ $226, \mathrm{~S}=0.883$; Final $\mathrm{R}$ indices $[I>2 \sigma(I)] R 1=0.0174, w R 2=0.0321 ; \mathrm{R}$ indices (all data) $R 1$ $=0.0285, w R 2=0.0329 ;$ Largest diff. peak and hole 1.657 and -0.834 e. $\AA^{-3}$.

Crystal data for $2 B r$. Empirical formula $\mathrm{C}_{17} \mathrm{H}_{11} \mathrm{BrN}_{3} \mathrm{O}_{3} \mathrm{Re} ; M W=571.40$. Monoclinic, Space group $P 2_{1} / n, a=11.7834(3), b=8.4832(3), c=17.0208(6) \AA, \beta=96.719(3)^{\circ}$, Volume $=$ 1689.73(9) $\AA^{3}, Z=4 ; \rho_{\mathrm{c}}=2.246 \mathrm{Mg} / \mathrm{m}^{3}, \mu=9.578 \mathrm{~mm}^{-1}$, crystal size 0.19 x 0.08 x $0.02 \mathrm{~mm}^{3}$; $\theta_{\min , \max }=2.97,32.00^{\circ}$. Reflections collected $=26852$, unique reflections $=5877[R(\mathrm{int})=$ 0.0619]. Max. and min. transmission $=0.813$ and 0.268. Number of parameters $=226, S=$ 1.046; Final $\mathrm{R}$ indices $[I>2 \sigma(I)] R 1=0.0323, w R 2=0.0591$; $\mathrm{R}$ indices (all data) $R 1=0.0409$, $w R 2=0.0617$; Largest diff. peak and hole 2.138 and -1.513 e. $\AA^{-3}$.

Crystal data for 3 Cl. Empirical formula $\mathrm{C}_{21} \mathrm{H}_{13} \mathrm{ClN}_{3} \mathrm{O}_{3} \mathrm{Re} ; M W=576.99$. Monoclinic, Space group $C 2 / c, a=10.6269(3), b=11.7796(3), c=30.7456(5) \AA, \square=90.507(2)^{\circ}$, Volume $=$ $3848.60(16) \AA^{3}, Z=8 ; \rho_{c}=1.992 \mathrm{Mg} / \mathrm{m}^{3}, \mu=6.482 \mathrm{~mm}^{-1}$, crystal size $0.15 \times 0.12 \times 0.08$ $\mathrm{mm}^{3} ; \theta_{\min , \max }=2.89$ to $31.45^{\circ}$. Reflections collected $=25394$, unique reflections $=6146$ $[R($ int $)=0.0479]$. Max. and min. transmission $=0.723$ and 0.496 . Number of parameters $=$ $311, S=1.129$; Final $\mathrm{R}$ indices $[I>2 \sigma(I)] R 1=0.0415, w R 2=0.0694 ; \mathrm{R}$ indices (all data) $R 1$ $=0.0522, w R 2=0.0725$; Largest diff. peak and hole 1.643 and $-0.794 \mathrm{e} . \AA^{-3}$. The phenyl ring was modelled as being disordered over two sets of sites with occupancies refined to $0.688(13)$ and its complement. Geometries and displacement parameters of the minor component were restrained to reasonable values.

Crystal data for $3 B$ r. Empirical formula $\mathrm{C}_{21} \mathrm{H}_{13} \mathrm{BrN}_{3} \mathrm{O}_{3} \mathrm{Re} ; M W=621.45$. Monoclinic, Space group $C 2 / c, a=10.6245(2), b=11.8726(2), c=30.9574(4) \AA, \beta=90.701(2)^{\circ}$, Volume = $3904.69(11) \AA^{3}, Z=8 ; \rho_{c}=2.114 \mathrm{Mg} / \mathrm{m}^{3}, \mu=8.299 \mathrm{~mm}^{-1}$, crystal size $0.30 \times 0.25 \times 0.06$ 
$\mathrm{mm}^{3} ; \theta_{\min , \max }=2.88,35.00^{\circ}$. Reflections collected $=56772$, unique reflections $=8586[R(\mathrm{int})$ $=0.0546]$. Max. and min. transmission $=0.653$ and 0.169. Number of parameters $=317, S=$ 1.087; Final $\mathrm{R}$ indices $[I>2 \sigma(I)] R 1=0.0375, w R 2=0.0850$; $\mathrm{R}$ indices (all data) $R 1=0.0453$, $w R 2=0.0884$; Largest diff. peak and hole 2.478 and -1.996 e. $\AA^{-3}$. The phenyl ring was modeled as being disordered over two sets of sites with occupancies refined to 0.639(9) and its complement. Geometries of the minor component were restrained to ideal values.

Crystal data for cis,cis-[Re(CO $\left.)_{2}(\mathrm{PyImPh})\left(\mathrm{NCCH}_{3}\right) \mathrm{Cl}\right]$. Empirical formula $\mathrm{C}_{20} \mathrm{H}_{17} \mathrm{ClN}_{5} \mathrm{O}_{2} \mathrm{Re} ; M W=$ 581.04. Monoclinic, Space group $P 2_{1} / n, a=13.1652(2), b=$ 10.76130(10), $c=15.3184(2) \AA, \square=110.527(2)^{\circ}$, Volume $=2032.43(4) \AA^{3}, Z=4 ; \rho_{c}=1.899$ $\mathrm{Mg} / \mathrm{m}^{3}, \mu=6.137 \mathrm{~mm}^{-1}$, crystal size $0.22 \times 0.14 \times 0.05 \mathrm{~mm}^{3}, \theta_{\min , \max }=3.16$ to $34.00^{\circ}$. Reflections collected $=55709$, unique reflections $=8283[R(\mathrm{int})=0.0376]$. Max. and min. transmission $=0.717$ and 0.404 . Number of parameters $=8283, S=1.106$; Final R indices $[I>2 \sigma(I)] R 1=0.0273, w R 2=0.0570 ; \mathrm{R}$ indices (all data) $R 1=0.0335, w R 2=0.0588$; Largest diff. peak and hole 2.079 and -0.738 e. $\AA^{-3}$. The chlorine atom and the carbonyl group trans to it are disordered between these two positions, with site occupancies refined to $0.756(6)$ and its complement. Geometries of the minor components were restrained to ideal values.

Crystal data for cis,cis-[Re(CO) $\left.)_{2}(\operatorname{PyImPh}) \operatorname{Br}\left(\mathrm{P}(\mathrm{OEt})_{3}\right)\right]$. Empirical formula $\mathrm{C}_{24} \mathrm{H}_{31} \mathrm{BrN}_{3} \mathrm{O}_{5.50} \mathrm{PRe} ; M W=746.60$. Monoclinic, Space group $P 2_{1} / c, a=16.3806(5), b=$ 12.9573(10), $c=12.8904(10) \AA, \beta=100.172(4)^{\circ}$, Volume $=2693.0(3) \AA^{3}, Z=4 ; \rho_{c}=1.841$ $\mathrm{Mg} / \mathrm{m}^{3}, \mu=6.096 \mathrm{~mm}^{-1}$, crystal size $0.22 \times 0.16 \times 0.11 \mathrm{~mm}^{3}, \theta_{\min , \max }=2.71,29.00^{\circ}$. Reflections collected $=40569$, unique reflections $=7154[R($ int $)=0.057]$. Max. and $\min$. transmission $=0.562$ and 0.335 . Number of parameters $=348, S=1.072$; Final R indices $[I>2 \sigma(I)] R 1=0.0316, w R 2=0.0753 ; \mathrm{R}$ indices (all data) $R 1=0.0378, w R 2=0.0783$; Largest diff. peak and hole 2.381 and -1.833 e. $\AA^{-3}$. The solvent diethyl ether molecule is disordered about a crystallographic inversion centre. Geometries were restrained to ideal values.

Crystal data for cis,trans-[Re(CO) $\left.)_{2}(\operatorname{Py} \operatorname{ImPh}) \operatorname{Br}\left(\boldsymbol{P}(\mathrm{OEt})_{3}\right)\right]$. Empirical formula $\mathrm{C}_{22} \mathrm{H}_{26} \mathrm{BrN}_{3} \mathrm{O}_{5} \mathrm{PRe} ; M W=709.54$. Triclinic, Space group $P \overline{1}, a=8.4078(5), b=11.7586(6)$, $c=12.8983(7) \AA, \alpha=98.323(4), \beta=102.735(5), \gamma=93.632(4)^{\circ}$, Volume $=1224.70(12) \AA^{3}$, 
$Z=2 ; \rho_{\mathrm{c}}=1.924 \mathrm{Mg} / \mathrm{m}^{3}, \mu=6.696 \mathrm{~mm}^{-1}$, crystal size $0.17 \times 0.11 \times 0.04 \mathrm{~mm}^{3}, \theta_{\min , \max }=3.52$, $29.00^{\circ}$. Reflections collected $=21461$, unique reflections $=6495[R($ int $)=0.0811]$. Max. and min. transmission $=0.755$ and 0.479 ; Number of parameters $=301, S=1.041$; Final $\mathrm{R}$ indices $[I>2 \sigma(I)] R 1=0.0492, w R 2=0.1083 ; \mathrm{R}$ indices (all data) $R 1=0.0606, w R 2=0.1129$; Largest diff. peak and hole 4.302 and -1.685 e. $\AA^{-3}$

\section{Computational calculations}

Time dependent density functional theory calculations were performed with GAUSSIAN $09^{51}$ in order to calculate the absorption spectra of all compounds. Prior to these calculations the structures were relaxed at the 6-311g** level of theory. Re atoms were treated with the Stuttgart-Dresden (SDD) Effective Core Potential ${ }^{52}$ and the effect of the solvent was mimicked with the PCM solvation model. ${ }^{53}$ The low-lying singlet-singlet excitation energies were calculated at the same level of theory.

\section{Electronic Supplementary Information}

Bond lengths and angles tables; excitation and emission profiles at room temperature and 77 $\mathrm{K}$; calculated orbital contours; calculated transitions; ${ }^{1} \mathrm{H}-\mathrm{NMR}$ progressions for the photochemical studies for all the complexes; CIF files for the X-ray crystallographic data. Full details of the structure determinations (except structure factors) have been deposited with the Cambridge Crystallographic Data Centre as CCDC 934464 (2Cl), 934465 (2Br), 934669 (3Cl), 934466 (3Br), 934657 (cis,cis-[Re(CO) $\left.\left.2(\mathbf{P y I m P h})\left(\mathrm{NCCH}_{3}\right) \mathrm{Cl}\right]\right), 934467$ (cis, cis$\left.\left[\operatorname{Re}(\mathrm{CO})_{2}(\mathbf{P y I m P h}) \operatorname{Br}\left(\mathrm{P}(\mathrm{OEt})_{3}\right)\right]\right), \quad 934468 \quad\left(\right.$ cis,trans $\left.-\left[\operatorname{Re}(\mathrm{CO})_{2}(\mathbf{P y} \mathbf{I m P h}) \operatorname{Br}\left(\mathrm{P}(\mathrm{OEt})_{3}\right)\right]\right)$. Copies of this information may be obtained free of charge from The Director, CCDC, 12 Union Road, Cambridge CB2 1EZ, UK (Fax: + 441223336 033; e-mail: deposit@ccdc.cam.ac.uk or www: http://www.ccdc.cam.ac.uk).

\section{Acknowledgments}

The work was supported by the Australian Research Council (DP0985481 and DP0986999) and Curtin University. JGV, BLR, PJW wish to thank Curtin University for their Australian Postgraduate Award. Access to the facilities at the Centre for Microscopy, Characterisation and Analysis, University of Western Australia, is also kindly acknowledged. PR and PJW also acknowledge NCI for the provision of computer time. 


\section{References}

1. M. Wrighton and D. Morse, J. Am. Chem. Soc, 1974, 96, 998-1003.

2. P. Giordano, S. Fredericks, M. Wrighton, and D. Morse, J. Am. Chem. Soc, 1978, 100, 2257-2259.

3. R. A. Kirgan, B. P. Sullivan, and D. P. Rillema, Top. Curr. Chem., 2007, 281, 45-100.

4. A. Vlček, Top. Organomet. Chem., 2010, 29, 73-114.

5. H. Yersin, A. F. Rausch, R. Czerwieniec, T. Hofbeck, and T. Fischer, Coord. Chem. Rev., 2011, 255, 2622-2652.

6. A. Rausch, H. Homeier, and H. Yersin, Top. Organomet. Chem., 2010, 29, 193-235.

7. Y. Chi and P. Chou, Chem. Soc. Rev., 2009, 39, 638-655.

8. V. Fernández-Moreira, F. L. Thorp-Greenwood, and M. P. Coogan, Chem. Commun., 2010, 46, 186-202.

9. K. Lo, Top. Organomet. Chem., 2010, 29, 115-158.

10. D. C. Grills and E. Fujita, J. Phys. Chem. Lett., 2010, 1, 2709-2718.

11. A. Kumar, S. Sun, and A. Lees, Top. Organomet. Chem., 2010, 29, 1-35.

12. O. Ishitani, K. Kanai, Y. Yamada, and K. Sakamoto, Chem. Commun., 2001, 15141515.

13. T. Morimoto, M. Ito, K. Koike, T. Kojima, T. Ozeki, and O. Ishitani, Chem. Eur. J., 2012, 18, 3292-3304.

14. K. Koike, J. Tanabe, S. Toyama, H. Tsubaki, K. Sakamoto, J. Westwell, F. Johnson, H. Hori, H. Saitoh, and O. Ishitani, Inorg. Chem., 2000, 39, 2777-2783.

15. P. Spellane, R. Watts, and A. Vogler, Inorg. Chem., 1993, 32, 5633-5636.

16. J. Smithback, J. Helms, E. Schutte, S. Woessner, and B. Sullivan, Inorg. Chem., 2006, 45, 2163-2174.

17. A. DelNegro, S. Woessner, B. Sullivan, D. Dattelbaum, and J. Schoonover, Inorg. Chem., 2001, 40, 5056-5057.

18. S. Hightower, R. Corcoran, and B. Sullivan, Inorg. Chem., 2005, 44, 9601-9603.

19. C.-O. Ng, L. T.-L. Lo, S.-M. Ng, C.-C. Ko, and N. Zhu, Inorg. Chem., 2008, 47, 74477449.

20. C.-C. Ko, A. W.-Y. Cheung, L. T.-L. Lo, J. W.-K. Siu, C.-O. Ng, and S.-M. Yiu, Coord. Chem. Rev., 2012, 256, 1546-1555.

21. C. Ko, L. Lo, C. Ng, and S. Yiu, Chem. Eur. J., 2010, 16, 13773-13782.

22. A. W.-Y. Cheung, L. T.-L. Lo, C.-C. Ko, and S.-M. Yiu, Inorg. Chem., 2011, 50, 4798-4810.

23. K. Koike, N. Okoshi, H. Hori, K. Takeuchi, O. Ishitani, H. Tsubaki, I. Clark, M. George, F. Johnson, and J. Turner, J. Am. Chem. Soc, 2002, 124, 11448-11455.

24. S. Sato, A. Sekine, Y. Ohashi, O. Ishitani, A. M. Blanco-Rodríguez, A. Vlček, T. Unno, and K. Koike, Inorg. Chem., 2007, 46, 3531-3540.

25. S. Sato, Y. Matubara, K. Koike, M. Falkenström, T. Katayama, Y. Ishibashi, H. Miyasaka, S. Taniguchi, H. Chosrowjan, N. Mataga, N. Fukazawa, S. Koshihara, K. Onda, and O. Ishitani, Chem. Eur. J., 2012, 18, 15722-15734.

26. L. A. Casson, S. Muzzioli, P. Raiteri, B. W. Skelton, S. Stagni, M. Massi, and D. H. Brown, Dalton Trans., 2011, 40, 11960-11967.

27. T. Sato, Y. Hirose, D. Yoshioka, and S. Oi, Organometallics, 2012, 31, 6995-7003.

28. S. J. Hock, L.-A. Schaper, W. A. Herrmann, and F. E. Kühn, Chem. Soc. Rev., 2013, 42, 5073-5089.

29. A. Gabrielsson, M. Busby, P. Matousek, M. Towrie, E. Hevia, L. Cuesta, J. Pérez, S. Zális, and A. Vlček, Inorg. Chem., 2006, 45, 9789-9797.

30. A. Vlček, Coord. Chem. Rev., 2006, 250, 1755-1762.

31. L. Benhamou, E. Chardon, G. Lavigne, S. Bellemin-Laponnaz, and V. Cesar, Chem. 
Rev., 2011, 111, 2705-2733.

32. X.-W. Li, H.-Y. Li, G.-F. Wang, F. Chen, Y.-Z. Li, X.-T. Chen, Y.-X. Zheng, and Z.L. Xue, Organometallics, 2012, 31, 3829-3835.

33. M. Itokazu, A. Polo, and N. Iha, J. Photochem. Photobiol. A, 2003, 160, 27-32.

34. V. W.-W. Yam, Chem. Commun., 2001, 789-796.

35. D. Stufkens and A. Vlček, Coord. Chem. Rev., 1998, 177, 127-179.

36. A. Vlček and S. Zális, Coord. Chem. Rev., 2007, 251, 258-287.

37. J.-Y. Hung, C.-H. Lin, Y. Chi, M.-W. Chung, Y.-J. Chen, G.-H. Lee, P.-T. Chou, C.-C. Chen, and C.-C. Wu, J. Mater. Chem., 2010, 20, 7682-7693.

38. P.-T. Chou, Y. Chi, M.-W. Chung, and C.-C. Lin, Coord. Chem. Rev., 2011, 255, 2653-2665.

39. P. J. Wright, S. Muzzioli, M. V. Werrett, P. Raiteri, B. W. Skelton, D. S. Silvester, S. Stagni, and M. Massi, Organometallics, 2012, 31, 7566-7578.

40. A. Palazzi, P. Sabatino, S. Stagni, S. Bordoni, V. G. Albano, and C. Castellari, J. Organomet. Chem., 2004, 689, 2324-2337.

41. V. Balzani, G. Bergamini, S. Campagna, and F. Puntoriero, Top. Curr. Chem., 2007, 280, 1-36.

42. M. V. Werrett, D. Chartrand, J. D. Gale, G. S. Hanan, J. G. MacLellan, M. Massi, S. Muzzioli, P. Raiteri, B. W. Skelton, M. Silberstein, and S. Stagni, Inorg. Chem., 2011, 50, 1229-1241.

43. J. P. Bullock, E. Carter, R. Johnson, A. T. Kennedy, S. E. Key, B. J. Kraft, D. Saxon, and P. Underwood, Inorg. Chem., 2008, 47, 7880-7887.

44. A. J. Amoroso, M. P. Coogan, J. E. Dunne, V. Fern Ndez-Moreira, J. B. Hess, A. J. Hayes, D. Lloyd, C. Millet, S. J. A. Pope, and C. Williams, Chem. Commun., 2007, 3066-3068.

45. A. E. Pierri, A. Pallaoro, G. Wu, and P. C. Ford, J. Am. Chem. Soc, 2012, 134, 1819718200.

46. R. Motterlini and L. E. Otterbein, Nat. Rev. Drug. Discov., 2010, 9, 728-743.

47. Z.-L. Xu, H.-X. Li, Z.-G. Ren, W.-Y. Du, W.-C. Xu, and J.-P. Lang, Tetrahedron, 2011, 67, 5282-5288.

48. J. Demas and G. Crosby, J. Phys. Chem., 1971, 75, 991-1024.

49. D. Eaton, Pure Appl. Chem., 1988, 60, 1107-1114.

50. G. M. Sheldrick, Acta Cryst. A, 2008, 64, 112-122.

51. M. J. Frisch, M. J. Frisch, G. W. Trucks, H. B. Schlegel, G. E. Scuseria, M. A. Robb, J. R. Cheeseman, G. Scalmani, V. Barone, B. Mennucci, G. A. Petersson, H. Nakatsuji, M. Caricato, X. Li, H. P. Hratchian, A. F. Izmaylov, J. Bloino, G. Zheng, J. L. Sonnenberg, M. Hada, M. Ehara, K. Toyota, R. Fukuda, J. Hasegawa, M. Ishida, T. Nakajima, Y. Honda, O. Kitao, H. Nakai, T. Vreven, J. A. Montgomery, Jr, J. E. Peralta, F. Ogliaro, M. Bearpark, J. J. Heyd, E. Brothers, K. N. Kudin, V. N. Staroverov, R. Kobayashi, J. Normand, K. Raghavachari, A. Rendell, J. C. Burant, S. S. Iyengar, J. Tomasi, M. Cossi, N. Rega, J. M. Millam, M. Klene, J. E. Knox, J. B. Cross, V. Bakken, C. Adamo, J. Jaramillo, R. Gomperts, R. E. Stratmann, O. Yazyev, A. J. Austin, R. Cammi, C. Pomelli, J. W. Ochterski, R. L. Martin, K. Morokuma, V. G. Zakrzewski, G. A. Voth, P. Salvador, J. J. Dannenberg, S. Dapprich, A. D. Daniels, Ö. Farkas, J. B. Foresman, J. V. Ortiz, J. Cioslowski, and D. J. Fox. Gaussian 09, Revision B.01.

52. D. Andrae, U. Haeussermann, M. Dolg, H. Stoll, and H. Preuss, Theor. Chim. Acta, 1990, 77, 123-141.

53. J. Tomasi, B. Mennucci, and R. Cammi, Chem. Rev., 2005, 105, 2999-3094. 
